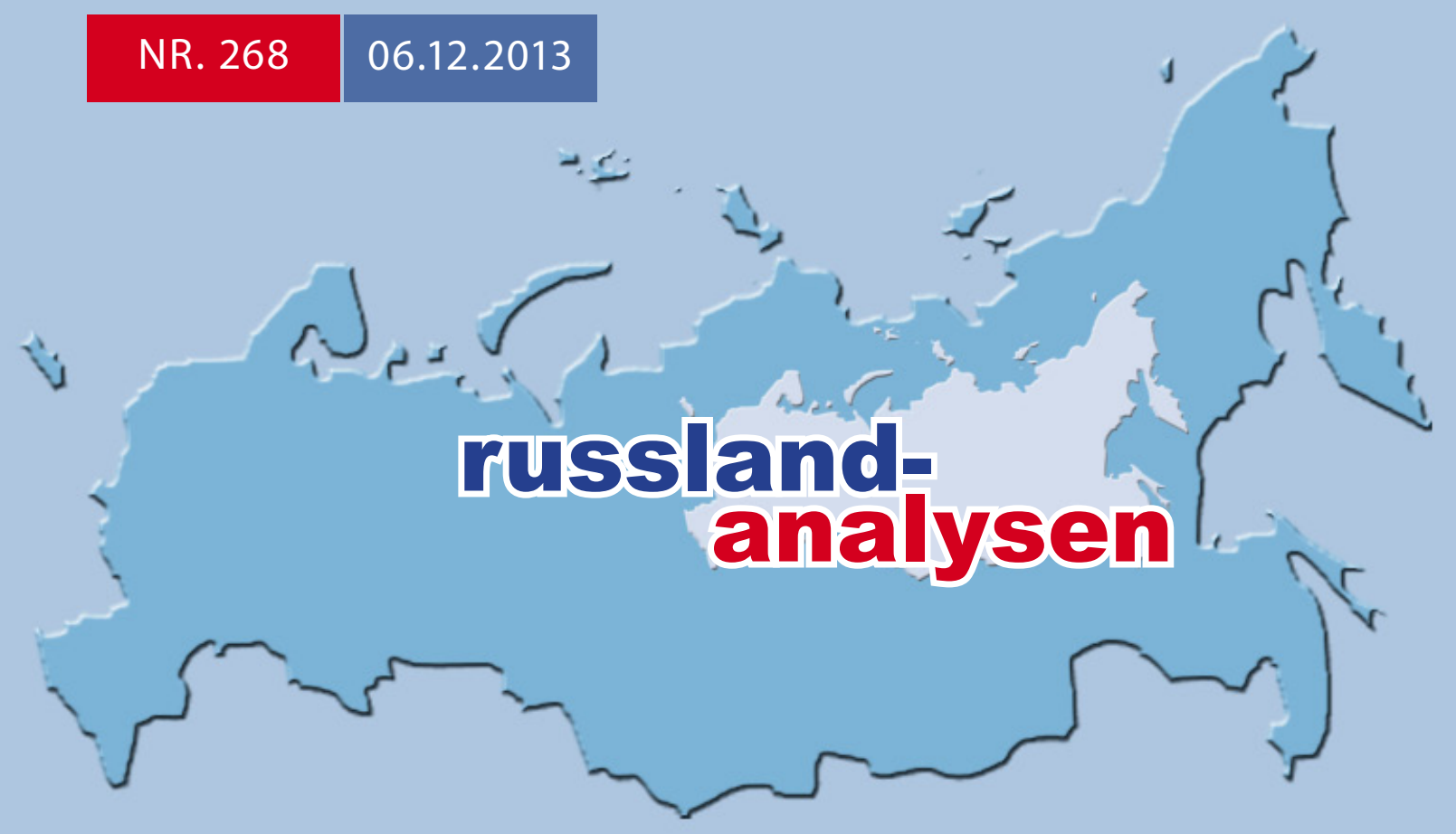

http://www.laender-analysen.de/russland/

\title{
SOTSCHI 2014
}

\section{ANALYSE}

Olimpstroj: Wie Olympia in Sotschi auf der grünen Wiese gebaut wird

Robert W. Orttung, Washington, DC

ANALYSE

Sotschi und sein kaukasisches Umfeld

Uwe Halbach, Berlin

CHRONIK

Sotschi, Olympia und der Nordkaukasus. Chronik Januar-November 2013

KARTE

Nordkaukasus - Administrative Übersicht

DOKUMENTATION

Die Ausgaben für die Olympiade in Sotschi im Vergleich 13

Kosten zentraler Olympiastadien

UMFRAGE

Die Olympiade in Sotschi in russischen Umfragen

- AUS RUSSISCHEN BLOGS

Verdammte Winterspiele

NOTIZEN AUS MOSKAU

Sotschi im Schnelldurchgang: Prestige, Selbstvergewisserung, Korruption, Viktor Jerofejew und der

Weißmeerkanal

Jens Siegert, Moskau

CHRONIK

Vom 22. November bis zum 5. Dezember 2013

- Deutsche Gesellschaft für Osteuropakunde e.V.
Forschungsstelle Osteuropa an der Universität Bremen
Alfried Krupp von Bohlen und Halbach Stiftung

\section{MANGOLD}




\title{
Olimpstroj: Wie Olympia in Sotschi auf der grünen Wiese gebaut wird
}

\author{
Robert W. Orttung, Washington, DC
}

\section{Zusammenfassung}

Die olympischen Spiele von Sotschi werden Russland über 50 Milliarden US-Dollar kosten. Das Staatsunternehmen »Olimpstroj «, das im Zentrum der Vorbereitungen steht, ist ein gutes Fallbeispiel, wie wohlvernetzte Insider der Eliten von dem derzeitigen politischen und wirtschaftlichen System des Landes profitieren.

\section{Die teuersten Olympischen Spiele aller Zeiten}

Die olympischen Spiele von Sotschi werden Russland über 50 Milliarden US-Dollar kosten und den zweifelhaften Ruhm der teuersten Spiele aller Zeiten erringen. Warum sind sie so teuer? Wer zahlt die Zeche? Wer profitiert von den Ausgaben?

Die Spiele in Sotschi sind so teuer, weil die Stadt vor allem als sommerliches Urlaubsziel bekannt war, bis Russland 2007 den Zuschlag zur Austragung der olympischen Winterspiele bekam. Sotschi war ein Ort, in dem Russen Strandurlaub machten. Skifahren war eine Möglichkeit für den Winter, doch hat sich in den nahegelegenen Bergen kein internationales Skigebiet entwickelt. Diese Situation machte Sotschi auf perverse Art für die Mitglieder des Internationalen Olympischen Komitees (IOC) attraktiv, die der Stadt gegenüber den Mitbewerbern aus Österreich und Südkorea den Vorzug gaben: Durch die Vergabe an Sotschi musste Russland ein nagelneues Wintersportgebiet mit dazugehörigen Einrichtungen und Komfort aufbauen.

2007 erschien Russland als eine gute Wahl als Austragungsort. Präsident Putin unterstützte das Projekt vehement, und das Land befand sich durch seine Öl- und Erdgasexporte wegen der Rekordpreise auf dem Weltmarkt in einem Aufschwung. Das wirtschaftliche Bild hat sich aber nach der Finanzkrise von 2008 eingetrübt; die Energiepreise sind gesunken, und es zeigte sich Russlands mangelnde Fähigkeit, seine Wirtschaft aus der Abhängigkeit von fossilen Energieexporten zu lösen. Putin hat jedoch Wort gehalten und die Erwartungen des IOC erfüllt, alle für die Vorbereitung der Spiele notwendigen Investitionen vorzunehmen.

Es gibt vier Kategorien von Ausgaben für die olympischen Spiele: für die eigentliche Durchführung der 17 Tage dauernden Spiele, für den Bau der Olympia-Anlagen, für die städtische Infrastruktur, die den Ansturm von Athleten, Zuschauern und Medien zu bewältigen hat, und schließlich für Sicherheitsmaßnahmen. Der Löwenanteil der Ausgaben entfällt auf die Infrastrukturprojekte, die aus Sotschi eine Stadt von Weltrang machen sollen.

\section{Wo das Geld herkommt}

Die meisten Gelder für Olympia stammen aus dem russischen Staatshaushalt. Im Westen treten üblicherweise lokale Entwicklungsgesellschaften als Organisatoren von Mega-Ereignissen wie Olympischen Spielen auf. Sie zielen auf einen Imagegewinn der jeweiligen Stadt, auf erhöhte Attraktivität und Komfort, eine Zunahme des Tourismus und damit ein Ankurbeln des Verkehrswertes der Immobilien. Während die Zentralregierung einen Teil der Ausgaben für Infrastruktur und Sicherheitsmaßnahmen übernimmt, wird der Olympiahaushalt typischerweise aus lokalen Quellen bestritten.

In Russland ist die Zentralregierung die treibende Kraft hinter den Spielen. Es sind Politiker und Unternehmen aus der Hauptstadt, und nicht lokale Akteure, die alle Schlüsselentscheidungen treffen. Dementsprechend stellt der Zentralhaushalt den überwiegenden Teil der Mittel zur Vorbereitung der Spiele zur Verfügung. Diese Gelder fließen in eine umfassende neue Infrastruktur in den Bereichen Bahn, Straße, Telekommunikation, Energieversorgung, Hotels und Sportanlagen.

Der Haushalt war 2007 ursprünglich auf lediglich 12 Milliarden US-Dollar geschätzt worden. Anfang 2013 wurden die notwendigen Ausgaben auf über 50 Milliarden berechnet. Allein der Staatshaushalt ist als "Quelle der letzten Zuflucht" in der Lage, derart große Summen aufzubringen.

$\mathrm{Zu}$ den übrigen Geldgebern gehören staatseigene und vom Staat kontrollierte Unternehmen wie Gazprom und die Russische Eisenbahn, die beide Monopolisten ihrer Branche sind. Auf Anweisung des Kreml übernehmen sie einen Teil der Kosten.

Putin hat auch wichtige Oligarchen wie Oleg Deripaska und Wladimir Potanin aufgefordert, das Ihre beizutragen. Hier stellt allerdings die Wneschekonombank Kredite zur Verfügung, die bis zu 90 Prozent der Investitionen abdecken. Die Oligarchen haben jedoch beklagt, dass die Olympischen Spiele sie zu Investitionen in Projekte nötigten, die sich in der Zukunft als kaum gewinnbringend herausstellen könnten. Während die gebauten Hotels auf die Winterspiele selbst zugeschnitten sind, ist unklar, ob der Tourismus auch zukünftig die geschaffenen Bettenzahlen nachfragen wird. Tatsächlich gibt es bereits Anzeichen für Schwierigkeiten und bevorste- 
hende Ausfälle bei der Begleichung von Schulden. Olympiainvestoren wie Gazprom, "Inter RAO«, "Renowa«, "Interros«, "Sberbank« und "Basowyj element« hätten darum gebeten, dass ihre Kredite umstrukturiert werden, berichtete die Zeitung "Wedomosti«. Die Unternehmen behaupteten, dass sie allesamt mit ihren Projekten Geld verlören und nicht in der Lage seien, die Kredite unter den jetzigen Bedingungen zurückzuzahlen.

\section{Wo geht das Geld hin?}

In den meisten Ländern veranstaltet ein dem IOC verantwortliches Organisationskomitee (OK) die Olympischen Spiele und sorgt dafür, dass die Sportstätten rechtzeitig vor Beginn der Eröffnungszeremonie fertiggestellt werden. Putin wählte jedoch einen anderen Ansatz, der besser zu seinem Regierungsstil passt als die in entwickelten Demokratien üblichen Methoden. Bei den Spielen in Russland dient das OK als Fassade für die Organisation, die die ganze Macht ausübt. Anstelle einer Berichterstattung an das IOC wollte Putin sicherstellen, dass er und seine Kollegen ohne lästige Aufsicht vorgehen können. Russlands Bauindustrie ist als einer der korruptesten Wirtschaftsbereiche bekannt und die russische Führung hatte zweifellos keinerlei Wunsch, die Arbeitsweisen der Branche für Außenseiter transparent zu machen.

Schlüsselakteur zur rechtzeitigen Fertigstellung der olympischen Sportstätten und der Infrastruktur ist "Olimpstroj«, eine Organisation, deren formale Bezeichnung "Staatliche Korporation für den Bau der olympischen Stätten und die Entwicklung der Stadt Sotschi als Gebirgskurort« lautet. Putin hatte »Olimpstroj«am 30. September 2007 durch ein föderales Gesetz ins Leben gerufen, um den Entwurf und den Bau der Sportstätten sowie der Infrastruktur für Verkehr, Energie, Tourismus und Sicherheit zu beaufsichtigen, deren Betrieb zu organisieren, Ausschreibungen vorzunehmen und den Bau der Olympiastätten sowie die Durchführung verwandter Maßnahmen zu beaufsichtigen. In den Dokumenten, die Russland als Teil der Bewerbung beim IOC vorgelegt hatte, war »Olimpstroj« nie erwähnt worden; erst nach dem Zuschlag an Russland war es in Erscheinung getreten.

Olimpstroj ist eine der nur sieben "staatlichen Korporationen" in Russland. Die anderen sind "Rosatom", "Rosstechnologii«, »Rosnano«, „Wneschekonombank«, die Agentur für die Versicherung von Vermögenseinlagen und der Fonds zur Reform der Wohnungs- und Kommunalwirtschaft. "Staatliche Korporationen" unterscheiden sich von privaten Unternehmen und staatlichen Agenturen. Formal sind sie als nichtkommerzielle Organisationen definiert. Sie sind nicht verpflichtet, detaillierte Jahresberichte vorzulegen, obwohl sie Zugang zu staatlichen Mitteln haben. Ihr besonderer Status macht es möglich, Gelder bei minimaler Aufsicht oder Einmischung zu kontrollieren. Dmitrij Medwedew hat als Präsident die Arbeit der staatlichen Korporationen kritisiert und versucht, ein höheres Niveau an Rechenschaftspflichten einzuführen. Das hatte jedoch ein Ende gefunden, als Putin erklärte, dass staatliche Korporationen "weder gut, noch schlecht« seien, sondern »notwendig«.

Eine Studie von Alexander Sokolow zu den Ausgaben von Olimpstroj hat gezeigt, dass die Aufwendungen für den Bau eines Stadiums, einer Straße oder einer Brücke in Russland sehr viel kostspieliger sind als vergleichbare Projekte in anderen Ländern. Seine Untersuchung von sieben zentralen Olympiastätten brachte hervor, dass die russischen Projekte 57,4\% mehr kosten als andere Projekte und legte nahe, dass die Differenzsumme von den Insidern abgezweigt wurden, die die wichtigsten Baufirmen kontrollieren.

Während die genaue Verteilung dieser Renten unklar ist, sind wenigstens einige Tatsachen bekannt. Firmen wie "Mostotrest" und "Strojgasmontash" von Arkadij Rotenberg, einem Freund von Putin aus Kindhaetstagen, haben Verträge über 7 Milliarden zu Olympiaprojekten erhalten, wie ein Bloomberg-Bericht mitteilt, der sich auf Firmen- und Regierungsberichte beruft. $\mathrm{Zu}$ diesen Projekten gehörten der Bau von Straßen und des Medienzentrums. So überrascht es kaum, dass die meisten Russen der Ansicht sind, die staatlichen Gelder würden ineffizient ausgegeben, wie eine Umfrage des Lewada-Zentrums vom Juni 2013 zeigt.

Rotenbergs Erfolg mit diesen Verträgen legt nahe, dass verschiedene Kategorien von Unternehmern unterschiedliche Beziehungen zu den Olympischen Spielen haben. Putins enge Freunde scheinen von der Großzügigkeit des Staates zu profitieren, während von Oligarchen aus den 1990er Jahren wie Peripaska und Potanin erwartet wird, etwas zur Olympiakasse beizusteuern.

\section{Wer steuert Olimpstroj?}

Die Regierung Russlands ernennt den Präsidenten von Olimpstroj und es hat nur wenig Stabilität bei der diesem Posten gegeben. Seit ihrer Schaffung hat die Korporation vier Präsidenten erlebt: Semjon Wajnschtok (2008), Viktor Kolodjaschnyj (2008/9), Tajmuras Bollojew (2009/11) und Sergej Gaplikow (seit 2011). Die schnelle Rotation an der Führungsspitze verweist auf schlechtes Management, den engen Zeithorizont der jeweils verantwortlichen Gruppen, und auf den Nährboden für Korruption. Im Gegensatz hierzu sind bei Organisationen, die offenbar über weniger absolute Macht verfügen, die Posten stabiler gewesen, nämlich die von Alexander Schukow, dem Präsidenten des Russischen 
Olympischen Komitees, und von Dmitrij Tschernyschenko, dem Leier des Organisationskomitees.

Vor seinem Amtsantritt als Präsident von Olimpstroj war Wajnschtok von 1999 bis 2007 Präsident des russischen Pipeline-Monopolisten »Transneft" gewesen. Nach Wajnschtoks Rückzug als Chef von »Transneft» hatte der Blogger Alexej Nawalnyj auf seinem Kreuzzug gegen Korruption dem Monopolisten vorgeworfen, im Rahmen eines sibirischen Pipelinebauprojektes vier Milliarden US-Dollar staatlicher Gelder unterschlagen zu haben. Nach seiner Absetzung bei Olimpstroj ging Wajnschtok erst nach London und dann nach Israel, wo er den Direktoriumsvorsitz bei Financial Levers übernahm.

Viktor Kolodjaschnyj, der nächste Präsident von Olimpstroj, war zuvor Bürgermeister von Sotschi und bekannt für seine Zementfabrik, die die Stadt mit Zement und Kolodjaschnyj angeblich mit Gewinnen zu Lasten der öffentlichen Kassen versorgte. Sein Problem bei Olimpstroj bestand darin, dass er gegenüber dem Gouverneur der Region Krasnodar Alexander Tkatschow wenig Macht hatte und deshalb von der Regionalregierung attackiert wurde - die wollte einen größeren Einfluss auf Olimpstroj, als ihr die Zentralregierung eingeräumt hatte.

Tajmuras Bollojew, ehemaliger Chef der Petersburger Brauerei »Baltika« und dritter Präsident von Olimpstroj, hatte während seiner Amtszeit offensichtlich Meinungsverschiedenheiten mit dem stellvertretenden Ministerpräsidenten Dmitrij Kosak.

Der vierte und derzeitige Chef von Olimpstroj, Sergej Gaplikow, war zuvor Ministerpräsident der Republik Tschuwaschien und stellvertretender Chef des Apparates der russischen Regierung.

Die Leitung von Olimpstroj wäre für jeden Manager eine ziemliche Herausforderung. Einerseits wird die Eröffnungsfeier am 7. Februar stattfinden, weswegen alle Anlagen zu diesem Zeitpunkt voll funktionstüchtig sein und angesichts des internationalen Medieninteresses hohen Qualitätsanforderungen genügen müssen. Selbst mit einem unbegrenzten Budget wird man nicht umhin können, rechtzeitig Ergebnisse zu liefern. Andererseits sitzt ein Präsident von Olimpstroj an der Quelle erheblicher Geldströme, weswegen viele Gruppen ein Interesse an Verträgen haben, mit denen ein Teil der Gelder in die eigene Richtung gelenkt werden kann.

Ein wichtiger Beweggrund hinter den Spielen ist darin zu sehen, wichtige Teile der Eliten mit Einnahmen zu versorgen. Wajnschtok war als formaler Chef des vom Staat kontrollierten Pipeline-Monopolisten »Transneft« (der selbst Renten für die Elite generiert) gut positioniert, um diese Funktion auszuüben. Kolodjaschnyj erfüllte ähnliche Ausgaben. Ihre kurze Amtszeit verweist darauf, dass es wohl Konflikte zwischen den verschiedenen Eliten gegeben hat, die die Geldströme unter ihre Kontrolle bringen wollen; und es verweist auf ein Unvermögen, ein rechtzeitiges Abhalten der Spiele zu gewährleisten. Bollojew und Gaplikow waren wohl neben der Umleitung von Renten in höherem Maße darauf konzentriert, Ergebnisse zu erzielen.

Das Führungschaos bei Olimpstroj hat offensichtlich Folgen für die Bauprojekte gehabt. Das Fischt-Stadion, der zentrale Austragungsort ist Ende 2013 immer noch nicht fertiggestellt. Nach Angaben der "Moscow Times« hat ein anonymer Insider, der an der Vorbereitung der Eröffnungszeremonie beteiligt war, die Rotationen an der Spitze von Olimpstroj für die Schwierigkeiten verantwortlich gemacht, weil es die Aufsicht über die Subunternehmen erschwere.

Einzige Konstante im Management von Olimpstroj ist Dmitrij Kosak, der gegenwärtig stellvertretender Ministerpräsident Russlands ist. Kosak ist zwar 2012 als Vorsitzender des Verwaltungsrates von Olimpstroj vom Minister für regionale Entwicklung Igor Sljunjajew abgelöst worden, beaufsichtigt aber weiterhin als stellvertretender Ministerpräsident das Olympia-Projekt. Kosaks Einfluss entstammt eher dessen informeller Verbindung zu Putin, als irgendeinem der formalen Positionen, die er innehatte. Putin hat ihn schon früher mit einer Reihe komplizierter Aufgaben betraut, etwa mit einer Rechtsreform, der Umgestaltung der Beziehungen zwischen Zentralregierung und Regionen sowie mit den Problemen im Nordkaukasus. Die verschiedenen Probleme bei Olimpstroj haben anscheinend Putins Vertrauen zu Dmitrij Kosak nicht schmälern können.

\section{Schlussfolgerungen}

In finanzieller Hinsicht sind die Olympischen Spiel in Sotschi ein Spiel für Russlands Elite. Zu den Nutznießern scheinen die reichen Freunde Putins zu gehören, die mit Olimpstroj Verträge über den Bau von Einrichtungen geschlossen haben, die nach den Spielen von geringem Nutzen sein könnten. Eine andere Gruppe innerhalb der Elite, die zu Investitionen in möglicherweise wenig gewinnträchtige Projekte genötigt wurde, beschwert sich lautstark. In der Folge könnte es sehr wohl zu einer Trennung innerhalb der Elite kommen zwischen denen, die profitieren, und jenen, die leer ausgehen.

Übersetzung aus dem Englischen: Hartmut Schröder

Informationen über den Autor und Lesetipps finden Sie auf der nächsten Seite. 
Über den Autor

Robert Orttung ist stellvertretender Direktor des Institute for European, Russian, and Eurasian Studies der Elliott School of International Affairs an der George Washington Universität und Gastwissenschaftler am Center for Security Studies (CSS) der Eidgenössischen Technischen Hochschule Zürich.

\section{Lesetipps}

- Orttung, Robert, Sufian Zhemukhov: The 2014 Sochi Olympic mega-project and Russia's political economy, in: Martin Müller (Hg.): Olympic Games in Sochi 2014: a great event for a great power? East European Politics 30, (erscheint 2014)

- Sokolov, A.: Insajderskij kontrol i inwestizii GK»Olimpstroj« [Insider-Kontrolle und Investitionen von GK»Olimpstroj «, in: Naukovedenie Nr. 4, 2012 (in russischer Sprache); <http://naukovedenie.ru/PDF/68evn412.pdf>

\section{ANALYSE}

\section{Sotschi und sein kaukasisches Umfeld}

Uwe Halbach, Berlin

\section{Zusammenfassung}

Das olympische Areal liegt am Westrand des Nordkaukasus, der in russischen und internationalen Sicherheitsanalysen mit bewaffnetem Aufstand assoziiert wird. Im September 2010 hob der damalige russische Präsident Medwedew die Region als die größte innere Herausforderung Russlands hervor. Der Europarat erklärte sie im selben Jahr zur herausragenden Gewaltzone in seinem Einzugsbereich. In den letzten Jahren erstreckte sich die Konfrontation zwischen bewaffneten Untergrundkräften und staatlichen Sicherheitsorganen weit über Tschetschenien hinaus, auf das sich die Wahrnehmung des Nordkaukasus lange Zeit beschränkt hatte. Als das IOC sich 2007 für Sotschi als Austragungsort für die Winterolympiade im Februar 2014 entschied, war dieser Prozess bereits in vollem Gange. Zudem hebt sich die »tscherkessische Frage« im Umfeld der Olympiade als historisches und gegenwartsbezogenes Thema ab. Sie fordert das Austragungsland Russland zur Auseinandersetzung mit Kolonialgewalt auf.

\section{Der Nordkaukasus als Russlands »inneres Ausland « und Gewaltzone}

In diesem Jahr drängte sich das Thema Sotschi 2014 in die internationale Berichterstattung über Russland. Da ging es um Korruption und Kostenexplosion beim Aufbau der olympischen Infrastruktur, um Proteste von Umweltschützern gegen den Bau von Autobahnen und gigantischen Sportstätten in Naturschutzgebieten, um klimatische Herausforderungen an eine Winterolympiade, die erstmals in einer subtropischen Zone stattfindet. Sicherheitspolitisch fällt für Russlands vorrangiges Prestigeprojekt jedoch das regionale Umfeld der Olympiade in Gewicht, der Nordkaukasus - eine Region, aus der im Wochentakt Gewaltereignisse gemeldet werden, auch wenn laut Aussage des FSB-Chefs Bortnikow die Zahl terroristischer Straftraten 2013 zurückgegangen sein soll.

Die Wahrnehmung dieser Region mit sieben Teilrepubliken der Russischen Föderation - von Adygeja im
Westen nahe der Schwarzmeerküste bis Dagestan im Osten am Kaspischen Meer - war lange Zeit auf Tschetschenien beschränkt. Die von zwei Kriegen erschütterte Teilrepublik bildet heute nicht mehr das Epizentrum bewaffneten Aufstands, auch wenn sie von nachhaltiger Befriedung noch weit entfernt ist. Das dem olympischen Areal am nächsten gelegene Territorium, auf das der in internationalen Sicherheitsanalysen mit »low level insurgency « bezeichnete Zustand zutrifft, ist die Teilrepublik Kabardino-Balkarien im mittleren Abschnitt des Nordkaukasus, rund $500 \mathrm{~km}$ von Sotschi entfernt. Während des ersten Tschetschenienkriegs (1994-96) war sie von Dschohar Dudajew, dem damaligen Führer der tschetschenischen Revolution, nach einer russischen Märchenfigur noch als die "schlafende Schöne« bezeichnet worden, weil sie unbehelligt vom Krieg in ihrer Nachbarschaft Touristen anzog. Das hat sich geändert - spätestens nachdem im Oktober 2005 ihre Hauptstadt Naltschik einem großflächigen Angriff bewaffneter Kämpfer 
eines islamistischen Netzwerks ausgesetzt war. In der Gewaltstatistik von 2012 stand Kabardino-Balkarien zwar nur an vierter Stelle unter den nordkaukasischen Teilrepubliken. Gleichwohl erregten einige Erscheinungen in Moskau Besorgnis. So ist der Anteil der russischen Bevölkerung durch Auswanderung gesunken - von $32 \%$ im Jahr 1989 auf rund 20 \% heute. Im Ostteil des Nordkaukasus, in Dagestan, Tchetschenien und Inguschetien, finden sich nur noch winzige Restbestände russischer Bevölkerung. Unter den ethnischen Russen wächst die Angst vor einer Ausbreitung des "Wahhabismus«. Mit diesem Schlagwort werden radikal-islamistische (salafistische) und militante (jihadistische) Tendenzen im überwiegend muslimischen Nordkaukasus bezeichnet. Gaben 2005 bei einer Umfrage der Medium Orient Information Agency nur sechs Prozent der befragten Russen in Kabardino-Balkarien dies als die bedrohlichste Entwicklung an, waren es 2012 schon 59 Prozent.

Am weitesten ragt aus der Gewaltstatistik heute Dagestan heraus. Von 144 Terrorakten, die nach FSBAngaben von Januar bis September 2013 verzeichnet wurden, entfielen 122 auf diese größte nordkaukasische Teilrepublik mit annähernd drei Millionen Einwohnern aus Dutzenden Volksgruppen. Sie ist zwar gut $1000 \mathrm{~km}$ vom olympischen Areal um Sotschi entfernt, doch räumliche Distanz spielt für die ins Innere Russlands ausgreifenden Terroranschläge mit nordkaukasischem Hintergrund keine Rolle. Der jüngste Anschlag dieser Art ereignete sich in Wolgograd am 21.Oktober 2013. Das Attentat auf einen Linienbus, das sechs Todesopfer forderte, wurde von einer jungen Frau aus dem dagestanischen Bergdorf Gunib ausgeführt, die mit ihrer Sprengstoffladung mehr als $800 \mathrm{~km}$ bis zum Tatort anreiste.

\section{Terrordrohungen gegen das Projekt Sotschi 2014}

An prominentester Stelle erklang eine Drohung gegen die Winterolympiade aus dem Mund Doku Umarows. Der Führer des »Kaukasus-Emirats« hob ein Moratorium für Terroranschläge gegen zivile Ziele in Russland wieder auf, das er im Februar 2012 verkündet hatte, und appellierte an die "Mudschahedin", die olympischen Spiele »mit allen uns von Allah erlaubten Mitteln zu verhindern«. Die Olympiade veranstalte »satanische Tänze auf den Gebeinen unserer Vorfahren, die gefallen sind und begraben wurden in unserem Land entlang der Küste des Schwarzen Meeres« - eine Anspielung auf die Niederwerfung des tscherkessischen Widerstandes durch die Armee des Zaren 1864. Die russischen Behörden reagierten relativ gelassen auf die Drohung, schlossen aber eine reale Gefahr für die olympischen Spiele nicht aus. Schon zuvor hatte es dafür Anzeichen gegeben. Im Februar 2011 verübten Terrorzellen in Kabardino-
Balkarien Anschläge gegen Ski-Gebiete am Elbrus. Sie richteten sich gegen ein weitgespanntes Tourismusprogramm, das von der Schwarzmeerküste bis zum Kaspischen Meer eine Kette von Kurorten und Ferienzentren als Maßnahme zur Modernisierung und Stabilisierung des Nordkaukasus errichten will, wurden aber auch als gezielte Vorbereitung für Anschläge im Umfeld der bevorstehenden olympischen Spiele gedeutet. Im Mai 2012 hob der FSB zehn Waffenlager in Abchasien aus, die u. a. Boden-Boden-Raketen enthielten und offenbar in Vorbereitung größerer Anschläge angelegt worden waren.

Am 1. September 2013 unterzeichnete Präsident Putin ein Sonderdekret über entsprechende Sicherheitsmaßnahmen. Es sieht für den Zeitraum vom 7. Januar bis zum 21. März 2014 für die Stadt Sotschi und ihre Umgebung eine Sicherheitszone vor, in der unter anderem Demonstrationen verboten werden. Der Demonstrationsbann richtet sich nicht nur gegen regimekritische Kräfte, sondern insbesondere gegen Aktivisten einer tscherkessischen Bewegung, die darauf aufmerksam machen wollen, dass die Olympiade auf dem ursprünglichen Siedlungsgebiet ihrer vor 150 Jahren vertriebenen Volksgruppe stattfindet. Etwa 40.000 Mann werden von den Sicherheitskräften allein in Sotschi (400.000 Einwohner) eingesetzt. Der Luftraum über und das Seegebiet vor der Stadt sollen mit Drohnen und Radar überwacht werden. In der Region Krasnodar, zu der Sotschi gehört, marschieren neben regulären Sicherheitskräften der Polizei, des FSB und des Föderalen Migrationsdienstes neu gegründete Kosakeneinheiten auf, um das olympische Areal vor "verdächtigen Elementen« zu schützen.

\section{Ethnische und islamistische Bewegungen am Südrand Russlands}

Beim Übergang in die nachsowjetische Periode waren es Bewegungen von Volksgruppen und territoriale Konflikte, die den Nordkaukasus aus dem sowjetischen Vielvölkerreich hervorhoben. In das kaukasische Ethnogramm mit seiner Vielzahl an Volksgruppen und Sprachen kam heftige Bewegung. Da trat eine "Volksfront« nach der anderen mit Forderungen nach mehr Autonomie für die eigene Gruppe in Erscheinung. Einige der Konflikte und Sezessionserscheinungen verschwanden bald wieder von der Tagesordnung, andere prägen bis heute das Bild regionaler Unruhe. Zum schlimmsten Gewaltereignis nachsowjetischer Geschichte wurde der Konflikt zwischen Tschetschenien und Russland, der Ende 1994 in offenen Krieg überging. Zwei Trends prägten nach dem Ende dieses ersten Kriegs 1996 die Entwicklung im Nordkaukasus: die »Dschihadisierung" und Ausweitung des Widerstands über Tschetschenien hinaus. Im bewaffneten Untergrund begann ein Pro- 
zess ideologischer Transformation. Da verschoben sich die Kampfparolen von einem nationalen zu einem als Dschihad präsentierten islamischen Widerstand. Die Protagonisten dieser »Dschihadisierung« lehnten Identifikation auf ethnischer, tribaler oder lokaler Grundlage $\mathrm{ab}$ und richteten ihre Kampfansage gegen den "nahen Feind «, gegen »Okkupanten« (russische Repräsentanten föderaler Sicherheitsorgane) und »Apostaten« (Repräsentanten lokaler kaukasischer Machtorgane), aber auch gegen »Ungläubige«s schlechthin. Besiegelt wurde dieser Prozess durch die Ausrufung eines "Kaukasus-Emirats" (Imarat Kavkaz) durch den letzten tschetschenischen Untergrundpräsidenten Doku (Dokka) Umarow im Oktober 2007. Von diesem Emirat, dem sich autonom agierende lokale Kampfverbände (dschama'at) im Nordkaukasus und seiner Umgebung zuordnen, gingen spektakuläre Terroranschläge auch im Inneren Russlands aus. Ramsan Abdulatipow, der gegenwärtige Republikführer Dagestans, hat einmal die rhetorische Frage gestellt: Warum hat das nachsowjetische Russland das Ende des historischen Kaukasuskriegs im Jahr 1864 noch nicht zum nationalen Gedenktag erhoben wie andere Ereignisse vaterländischer Geschichte? Seine Antwort: Weil der Krieg noch nicht vorbei ist.

Eine Vielzahl von Faktoren ist hier zu berücksichtigen. Gewalt ist nicht auf den bewaffneten Untergrund beschränkt. Die Bevölkerung in einigen kaukasischen Teilrepubliken wird nicht nur von Rebellen, sondern auch von staatlichen Gewaltakteuren bedrängt, die mit Maßnahmen wie der Entführung von Terrorverdächtigen und Repressionen gegen deren Familien außerhalb von Rechtsstaatlichkeit agieren. Zu gravierenden Missständen in der lokalen und föderalen Regierungsführung treten sozialökonomische Probleme, die aus einigen Teilen des Nordkaukasus die Armutsperipherie der Russischen Föderation machen. Der korrupte Zustand der weltlichen Justizorgane sorgte dafür, dass der Ruf nach der Scharia und islamischer Staatlichkeit vor allem in der jungen Generation Popularität erlangte.

\section{Die tscherkessische Frage}

Diese Entwicklung hat ethnisch-territoriale Konfliktlinien und nationale Bewegungen in den Hintergrund treten lassen, aber nicht verdrängt. Im Ostteil der Region treten auch heute Grenzkonflikte zwischen Tschetschenien und seinen Nachbarrepubliken zu Tage. Im
Westteil drängt sich die "tscherkessische Frage« in den Wahrnehmungskontext der Winterolympiade in Sotschi. Nach der im Juli 2007 getroffenen Entscheidung des Internationalen Olympischen Komitees für diesen Austragungsort hat das russische Prestigeprojekt eine weltweite tscherkessische Diaspora in Bewegung versetzt. Sie liefert ein Beispiel für ein Phänomen, das in der Nationalismus- und Identitätsforschung mit »long distance nationalism« bezeichnet wird. Einige Millionen Nachkommen der vor 150 Jahren aus ihrer Heimat vertriebenen Tscherkessen leben heute in der Türkei, in Staaten des Mittleren Ostens, auf dem Balkan, in den USA und in Deutschland. Im Nordaukasus leben Reste der einstmals größten Volksgruppe der Region in den beiden bi-nationalen "Bindestrich-Republiken« Karatschajewo-Tscherkessien und Kabardino-Balkarien und in der kleinen Republik Adygeja. Was im 19. Jahrhundert noch mit dem Sammelbegriff Tscherkessen bezeichnet wurde, untergliederte die sowjetische Nationalitätenpolitik in diverse ethnonyme und Gebietseinheiten. Es sind vor allem drei Anliegen, die eine weltweite tscherkessische Bewegung umtreiben: 1. Anerkennung der an ihrer Volksgruppe verübten kolonialen Gewalt, 2. Wiederansiedlungsprogramme in ihrer nordkaukasischen Heimat - derzeit besonders für tscherkessische Flüchtlinge aus Syrien, 3. Vereinigung der historischen Siedlungsgebiete ihrer Volksgruppe zu einer Verwaltungseinheit. Beim Verhältnis zur Winterolympiade nehmen ihre Vertreter unterschiedliche Haltungen ein. Die einen wollen die Olympiade als internationale Bühne nutzen, um die tragische Geschichte ihres Volkes in Erinnerung zu rufen, andere fordern zum Boykott auf und verweisen dabei auf einen "Genozid", der vor 150 Jahren auf dem heutigen olympischen Areal begangen wurde. Russland hätte die Winterolympiade in Sotschi dazu nutzen können, sich der »tscherkessischen Frage« zu öffnen. In der Geschichte der von Präsident Putin beschworenen »einzigartigen Vielvölker-Zivilisation« Russland hat vernichtende Kolonialgewalt aber kaum Platz. Die Abwehrhaltung gegenüber der "tscherkessischen Frage« wuchs in Moskau noch dadurch, dass sich Georgien seit 2010 dieses Themas im Rahmen einer intensivierten Politik gegenüber dem Nordkaukasus angenommen hatte. So wurde es schon weit im Vorfeld der Winterolympiade von 2014 politisiert.

Über den Autor

Dr. Uwe Halbach ist Wissenschaftler in der Forschungsgruppe Osteuropa und Eurasien der Stiftung Wissenschaft und Politik.

Lesetipps finden Sie auf der nächsten Seite. 
Lesetipps

- Babich, Irina: Mobilization of the Circassians in view of the 2014 Olympic Games, in: Central Asia and the Caucasus, 13.2012, Nr. 2, S. 22-37;

- Halbach, Uwe, Michail Logvinov: Das Kaukasus Emirat und der internationale Jihadismus [=SWP-Aktuell 41, Juli 2012], Berlin 2012; <http://www.swp-berlin.org/fileadmin/contents/products/aktuell/2012A41_hlb_logvinov.pdf>

- International Crisis Group: The North Caucasus. The Challenge of Integration Part II: Islam, the Insurgency and Counter Insurgency [= Europe Report Nr. 221], 19. Oktober 2012; <http://www.crisisgroup.org/ /media/Files/ europe/caucasus/221-the-north-caucasus-the-challenges-of-integration-ii-islam-the-insurgency-and-counter-insur gency.pdf>

\section{Sotschi, Olympia und der Nordkaukasus. Chronik Januar-November 2013}

\begin{tabular}{|c|c|}
\hline 06.01 .2013 & $\begin{array}{l}\text { Sicherheitskräfte töten im Rayon Baksan (Kabardino Balkarien) drei mutmaßliche Untergrund- } \\
\text { kämpfer. Nach offizieller Auskunft hatten diese während der Weihnachtsgottesdienste Terroranschläge } \\
\text { geplant gehabt. }\end{array}$ \\
\hline 15.01 .2013 & $\begin{array}{l}\text { Präsident Wladimir Putin gründet per Erlass eine Staatskommission zur Vorbereitung und Durch- } \\
\text { führung der 22. Olympischen Winterspiele sowie der 11. Paraolympischen Winterspiele } 2014 \text { in } \\
\text { Sotschi. Zum Vorsitzenden wird der Stellvertretende Ministerpräsident Dmitrij Kosak bestimmt. }\end{array}$ \\
\hline 15.01 .2013 & $\begin{array}{l}\text { In Machatschkala töten Unbekannte Magomed Magomedow, Richter am Obersten Gericht von } \\
\text { Dagestan. }\end{array}$ \\
\hline 16.01 .2013 & $\begin{array}{l}\text { Sicherheitskräfte töten bei einer Spezialoperation in Tyrnyaus (Kabardino-Balkarien) zwei mutmaß- } \\
\text { liche Untergrundkämpfer sowie eine Frau, die sie unterstützte. }\end{array}$ \\
\hline $\begin{array}{l}23 .- \\
24.01 .2013\end{array}$ & $\begin{array}{l}\text { Bei Gefechten russischer Sicherheitskräfte mit Untergrundkämpfern werden im Rayon Wedeno } \\
\text { (Tschetschenien) zwei Soldaten getötet und fünf weitere verletzt. }\end{array}$ \\
\hline 25.01 .2013 & $\begin{array}{l}\text { In der Nähe von Tschegem (Kabardino-Balkarien) werden bei einer Spezialoperation der Sicherheits- } \\
\text { kräfte drei Untergrundkämpfer getötet. }\end{array}$ \\
\hline 06.02 .2013 & $\begin{array}{l}\text { Präsident Wladimir Putin besucht Sotschi, um sich ein Bild von den Vorbereitungen für die Winter- } \\
\text { Olympiade } 2014 \text { zu machen. Am Abend trifft er mit Vertretern des Internationalen Olympischen } \\
\text { Komitees zusammen. Alle Seiten zeigen sich erfreut über den Stand der Arbeiten. }\end{array}$ \\
\hline 07.02 .2013 & $\begin{array}{l}\text { Präsident Wladimir Putin entlässt Achmed Bilalow als Vize-Präsidenten des russischen Olympischen } \\
\text { Komitees und als Vorsitzenden des Staatsunternehmens »Kurorte des Nordkaukasus«. Bilalow ist am } \\
\text { Bau mehrerer Olympia-Objekte beteiligt. Putin hatte am Vortag in Sotschi Bauverzögerungen und } \\
\text { Baukostensteigerungen heftig kritisiert. Gegen Viktor Lutschinkin, den Stabschef des Präsidenten } \\
\text { de staatlichen Korporation »Olimpstroj«, wird ein Untersuchungsverfahren wegen des Verdachts auf } \\
\text { Diebstahl von } 900 \text { Mio. Rubel (ca. € } 22 \text { Mio.) eingeleitet. }\end{array}$ \\
\hline 07.02.2013 & $\begin{array}{l}\text { Präsident Wladimir Putin und Jacques Rogge, Präsident des Internationalen Olympischen Komitees, } \\
\text { nehmen an der Zeremonie "Ein Jahr bis zu den Spielen« in Sotschi teil und eröffnen den Countdown } \\
\text { bis zum Beginn der Winter-Olympiade } 2014 .\end{array}$ \\
\hline 12.02 .2013 & $\begin{array}{l}\text { Bei einer Spezialoperation der Sicherheitskräfte zwischen den Rayons Derbent und Tabasaransk } \\
\text { (Dagestan) werden fünf Untergrundkämpfer getötet. }\end{array}$ \\
\hline $\begin{array}{l}13 .- \\
14.02 .2013\end{array}$ & $\begin{array}{l}\text { Bei der Explosion eines Sprengsatzes bei einem Polizeiposten vor Chasawjurt (Dagestan) werden vier } \\
\text { Polizisten getötet und fünf weitere verletzt. Während der folgenden Spezialoperation werden sechs } \\
\text { Untergrundkämpfer und ein Soldat getötet. }\end{array}$ \\
\hline 18.02 .2013 & $\begin{array}{l}\text { Achmed Bilalow tritt von seinem Amt als Vizepräsident des »Russischen Olympischen Komitees» } \\
\text { zurück. Präsident Putin hatte bei einer Visite in Sotschi Bauverzögerungen und Kostensteigerungen } \\
\text { heftig kritisiert. }\end{array}$ \\
\hline
\end{tabular}




\begin{tabular}{|c|c|}
\hline 22.02.2013 & Sicherheitskräfte töten an der tschetschenisch-inguschetischen Grenze zwei Untergrundkämpfer. \\
\hline 09.03.2013 & Unbekannten töten einen Richter des Föderalgerichts in Isberbasch (Dagestan). \\
\hline 09.03 .2013 & $\begin{array}{l}\text { Im Rayon Chasawjurt (Dagestan) werden zwei Untergrundkämpfer bei einem Feuergefecht mit } \\
\text { Sicherheitskräften getötet. }\end{array}$ \\
\hline 12.03.2013 & Sicherheitskräfte töten im Rayon Baksan (Kabardino-Balkarien) drei mutmaßliche Untergrundkämpfer. \\
\hline 16.03 .2013 & $\begin{array}{l}\text { An der tschetschenisch-inguschetischen Grenze kommt es zu Schusswechseln zwischen Sicherheits- } \\
\text { kräften und Untergrundkämpfern. Sieben Untergrundkämpfer werden getötet. }\end{array}$ \\
\hline 08.04.2013 & $\begin{array}{l}\text { Bei einer Spezialoperation russischer Sicherheitskräfte unweit von Nasran (Inguschetien) werden vier } \\
\text { Untergrundkämpfer sowie ein Soldat getötet. }\end{array}$ \\
\hline 24.04 .2013 & $\begin{array}{l}\text { Bei einer Anti-Terror-Operation der Sicherheitskräfte werden im Gunibskij Rayon (Dagestan) zwei } \\
\text { mutmaßliche Untergrundkämpfer getötet. }\end{array}$ \\
\hline 27.04 .2013 & $\begin{array}{l}\text { Bei einer Fahrzeugkontrolle im Rayon Chiw (Dagestan) töten Sicherheitskräfte drei mutmaßliche } \\
\text { Untergrundkämpfer. }\end{array}$ \\
\hline 28.04.2013 & $\begin{array}{l}\text { Bei einer Spezialoperation von Sicherheitskräften werden im Rayon Kisiljurt (Dagestan) zwei mutmaß- } \\
\text { liche Untergrundkämpfer getötet. }\end{array}$ \\
\hline 02.05 .2013 & $\begin{array}{l}\text { Das Nationale Olympische Komitee Georgiens beschließt offiziell, dass Georgien eine Mannschaft } \\
\text { zur Winterolympiade in Sotschi entsendet. }\end{array}$ \\
\hline 02.05 .2013 & $\begin{array}{l}\text { Die Innenbehörden des Föderalbezirks Nordkaukasus teilen mit, dass im ersten Quartal } 2013 \text { bei } \\
121 \text { terroristischen Vorfällen im Föderalbezirk } 73 \text { Untergrundkämpfer getötet und } 88 \text { weitere fest- } \\
\text { genommen wurden. }\end{array}$ \\
\hline $\begin{array}{l}\text { 08.- } \\
09.05 .2013\end{array}$ & $\begin{array}{l}\text { Bei Spezialoperationen der Sicherheitskräfte in den Rayons Karabudachkent und Kumtorkalinsk (Da- } \\
\text { gestan) werden sieben Untergrundkämpfer getötet. Bei den Einsätzen werden auch drei Angehörige } \\
\text { Sicherheitskräfte verletzt, ein Soldat kommt ums Leben. }\end{array}$ \\
\hline 10.05.2013 & $\begin{array}{l}\text { Präsident Wladimir Putin empfängt den britischen Premierminister David Cameron in Sotschi. Im } \\
\text { Zentrum des Gesprächs steht die Regulierung des Konflikts in Syrien. Darüber hinaus werden die } \\
\text { Zusammenarbeit bei perspektivreichen Energieprojekten und die Kooperation der Sicherheitsdienste } \\
\text { während der Winter-Olympiade vereinbart. }\end{array}$ \\
\hline 15.05 .2013 & $\begin{array}{l}\text { räsident Wladimir Putin empfängt den Premierminister Vietnams Nguyen Tan Dung in Sotschi. } \\
\text { n Zentrum des Geprächs steht die wirtschaftliche Zusammenarbeit beider Länder. }\end{array}$ \\
\hline 20.05.2013 & $\begin{array}{l}\text { In Orechowo-Suewo (Moskauer Gebiet) werden zwei mutmaßliche Untergrundkämpfer von Sicher- } \\
\text { heitskräften getötet und ein dritter festgenommen. Das Nationale Anti-Terrorkomitee erklärt, die } \\
\text { drei hätten einen Terroranschlag in Moskau vorbereitet. }\end{array}$ \\
\hline 21.05.2013 & $\begin{array}{l}\text { Bei einer Spezialoperation der Sicherheitskräfte werden zwei Untergrundkämpfer in einem Stadtteil } \\
\text { von Nasran (Republik Inguschetien) getötet. Nach Angaben des Republikoberhauptes Junusbek } \\
\text { Jewkurow war einer der Getöteten ein enger Vertrauter von Doku Umarow, der als Anführer des } \\
\text { Untergrundkampfes gilt. }\end{array}$ \\
\hline 23.05.2013 & $\begin{array}{l}\text { ei einer Spezialoperation der Sicherheitskräfte in Chasawjurt (Dagestan) werden zwei Untergrund- } \\
\text { ämpfer getötet. Bei einem weiteren Anti-Terroreinsatz im Dorf Gubden (Dagestan) kommen ein } \\
\text { oldat der Inlandstruppen und ein Untergrundkämpfer ums Leben. }\end{array}$ \\
\hline 24.05 .2013 & $\begin{array}{l}\text { Präsident Wladimir Putin trifft in Sotschi mit Vertretern der russischen Kinoindustrie zusammen. Er } \\
\text { regt an, eine Charta auszuarbeiten, die der staatlichen Filmförderung zur Orientierung dienen kann. }\end{array}$ \\
\hline 26.05 .2013 & $\begin{array}{l}\text { Präsident Wladimir Putin empfängt in Sotschi seinen ukrainischen Amtskollegen Viktor Janukowitsch. } \\
\text { Das Gespräch behandelt Fragen der bilateralen Handelsbeziehungen und die Zusammenarbeit im } \\
\text { Rahmen der GUS. }\end{array}$ \\
\hline 27.05 .2013 & $\begin{array}{l}\text { Präsident Wladimir Putin empfängt in Sotschi Patriarch Kirill und Theophilos III, den Patriarchen } \\
\text { der Orthodoxen Kirche in Jerusalem. Das Gespräch betrifft die Situation im Nahen Osten sowie die } \\
\text { Beziehungen der beiden Kirchen. }\end{array}$ \\
\hline 01.06 .2013 & $\begin{array}{l}\text { Sicherheitskräfte töten im Rajon Tscherek (Republik Kabardino-Balkarien) in einem Feuergefecht } \\
\text { zwei Personen, die die regionalen Untergrundkämpfer mit Waffen beliefert haben. }\end{array}$ \\
\hline
\end{tabular}




\begin{tabular}{|c|c|}
\hline 08.06 .2013 & $\begin{array}{l}\text { Bei einem Angriff von Untergrundkämpfern auf einen Polizeiposten in Naltschik (Republik Ka- } \\
\text { bardino-Balkarien) werden ein Polizist sowie ein Angreifer getötet. }\end{array}$ \\
\hline 11.06 .2013 & $\begin{array}{l}\text { Bei einem Überfall durch Untergrundkämpfer im Rayon Nowolakskij (Dagestan) werden drei } \\
\text { Angehörige einer Sondereinheit sowie zwei Angreifer getötet. Außerdem werden zwei Zivilpersonen } \\
\text { verletzt. Im Rayon Chasawjurt (Dagestan) töten Sicherheitskräfte drei Untergrundkämpfer, als es bei } \\
\text { einer Fahrzeugkontrolle zu einem Feuergefecht kommt. }\end{array}$ \\
\hline 29.06 .2013 & $\begin{array}{l}\text { Bei der Verfolgung von Untergrundkämpfern im Rayon Schatoj (Republik Tschetschenien), werden } \\
\text { zwei Soldaten getötet und siebzehn weitere verwundet. Bei einer Anti-Terror-Operation in den Rayons } \\
\text { Urvanskij und Tscherek (Republik Kabardino-Balkarien) wird ein Untergrundkämpfer getötet, vier } \\
\text { weitere werden festgenommen. }\end{array}$ \\
\hline $\begin{array}{l}06 .- \\
07.07 .2013\end{array}$ & $\begin{array}{l}\text { In Bujnaksk (Dagestan) werden zwei Untergrundkämpfer von Sicherheitskräften getötet. Die Kämpfer } \\
\text { hatten zuvor eine Polizeistreife angegriffen. }\end{array}$ \\
\hline 13.07.2013 & $\begin{array}{l}\text { Bei einer Spezialoperation der Sicherheitskräfte im Sunschenskij Rayon werden zwei Untergrund- } \\
\text { kämpfer getötet und ein Sonderpolizist verletzt. }\end{array}$ \\
\hline $\begin{array}{l}14 .- \\
15.07 .2013\end{array}$ & $\begin{array}{l}\text { Im Rayon Lakskij (Dagestan) werden vier Untersuchungsbeamte von Unbekannten getötet. In der } \\
\text { Folge wird eine Anti-Terror-Operation in den Rayons Lakskij und Kuli ausgerufen, bei der zwei wei- } \\
\text { tere Sicherheitskräfte ums Leben kommen. }\end{array}$ \\
\hline 18.07.2013 & $\begin{array}{l}\text { Bei einer Anti-Terror-Operation im Rayon Baksan (Republik Kabardino-Balkarien) werden vier } \\
\text { Untergrundkämpfer getötet, die nach Aussage der Sicherheitsbehörden einen Terroranschlag in der } \\
\text { Republik geplant hatten. }\end{array}$ \\
\hline 19.07.2013 & $\begin{array}{l}\text { Präsident Wladimir Putin empfängt in einem Trainingszentrum im Gebiet Moskau Sportler und } \\
\text { Preisträger der Universiade in Kasan. Er bedankt sich für die Leistung der russischen Mannschaft, } \\
\text { die dank der Teilnahme vieler Olympia-Sportler mit } 155 \text { von } 353 \text { Goldmedaillen als weitaus Beste } \\
\text { abschneidet. China folgt mit } 26 \text { Goldmedaillen. }\end{array}$ \\
\hline 23.07.2013 & $\begin{array}{l}\text { In einem Vorort von Machatschkala (Dagestan) greifen zwei Untergrundkämpfer Sicherheitskräfte } \\
\text { an. Drei Polizisten werden, verletzt, die beiden Angreifer werden getötet. }\end{array}$ \\
\hline $\begin{array}{l}06 .- \\
07.08 .2013\end{array}$ & $\begin{array}{l}\text { Bei einer Fahrzeugkontrolle in Naltschik (Kabardino-Balkarien) kommt es zu einer Schießerei zwischen } \\
\text { Sicherheitskräften und Untergrundkämpfern. Vier Insurgenten werden getötet, ein Polizist wird verletzt. }\end{array}$ \\
\hline 17.08.2013 & $\begin{array}{l}\text { Sicherheitskräfte töten im Rayon Karabudachkent (Dagestan) drei Untergrundkämpfer, darunter } \\
\text { den mutmaßlichen Anführer der Kämpfer von Kaspijsk. }\end{array}$ \\
\hline 17.08.2013 & $\begin{array}{l}\text { Präsident Wladimir Putin, sein kasachischer Amskollege Nursultan Nasarbajew sowie Ministerprä- } \\
\text { sident Dmitrij Medwedew besuchen gemeinsam einen internationalen Sambo-Wettkampf in Sotschi. }\end{array}$ \\
\hline 18.08.2013 & $\begin{array}{l}\text { Sondereinheiten der russischen Sicherheitskräfte töten in Chasawjurt (Dagestan) drei Untergrund- } \\
\text { kämpfer, die sich in einem Haus verschanzt hatten. }\end{array}$ \\
\hline $\begin{array}{l}20 .- \\
21.08 .2013\end{array}$ & $\begin{array}{l}\text { Mitarbeiter des Inlandsgeheimdienstes töten bei einem Sondereinsatz in Bujnaks (Dagestan) neun } \\
\text { Untergrundkämpfer. Unter ihnen ist ein Anführer der Kämpfer im Nordkaukasus, Bammatchan } \\
\text { Schejchow. Bei einer Vergeltungsaktion in der Nacht darauf wird ein Soldat getötet, ein weiterer verletzt. }\end{array}$ \\
\hline 23.08 .2013 & $\begin{array}{l}\text { Präsident Wladimir Putin unterschreibt einen Erlass über besondere Sicherheitsmaßnahmen während } \\
\text { der Winterolympiade und Paraolympics in Sotschi. Demnach sind in Sotschi von Januar bis Ende } \\
\text { März } 2014 \text { keine Mahnwachen und Demonstrationen erlaubt. }\end{array}$ \\
\hline 05.09 .2013 & $\begin{array}{l}\text { Bei einer Spezialoperation der Sicherheitskräfte im Rayon Urjen (Republik Kabardino-Balkarien) } \\
\text { werden sechs Untergrundkämpfer getötet. }\end{array}$ \\
\hline 14.09 .2013 & $\begin{array}{l}\text { Präsident Wladimir Putin empfängt den FIFA-Präsidenten Joseph Blatter in Sotschi. Auf dem Treffen } \\
\text { vereinbaren Blatter und der Gazprom-Vorsitzende Alexej Miller eine offizielle Partnerschaft von } \\
2015 \text { - } 2018 \text { zur Vorbereitung der Fußballweltmeisterschaft in Russland. }\end{array}$ \\
\hline $\begin{array}{l}15 .- \\
16.09 .2013\end{array}$ & $\begin{array}{l}\text { Bei einem Anschlag eines Selbstmordattentäters auf eine Stelle des Innenministeriums im Rayon } \\
\text { Sunshenskij (Republik Tschetschenien) werden drei Polizisten getötet und vier weitere verletzt. }\end{array}$ \\
\hline 16.09 .2013 & $\begin{array}{l}\text { Präsident Wladimir Putin hält ein Treffen über den Stand der Vorbereitungen zur Olympiade in Sotschi } \\
\text { ab. Er weist den Stellvertretenden Ministerpräsidenten Dmitrij Kosak an, ihn alle zwei Wochen über } \\
\text { den Fortschritt der Vorbereitungen zu informieren. }\end{array}$ \\
\hline
\end{tabular}




\begin{tabular}{|c|c|}
\hline 23.09 .2013 & $\begin{array}{l}\text { Bei einem Anschlag eines Selbstmordattentäters vor einer Polizeistation im Rayon Tabasaransk (Da- } \\
\text { gestan) werden ein Polizist und ein Migrationsbeamter getötet. } 14 \text { Polizisten und zwei Zivilisten } \\
\text { werden durch die Autobombe zum Teil schwer verletzt. }\end{array}$ \\
\hline 23.09 .2013 & $\begin{array}{l}\text { Präsident Wladimir Putin empfängt in Sotschi die Staatschefs der Organisation des Vertrags über } \\
\text { kollektive Sicherheit (ODKB). Die Teilnehmer besprechen mögliche Gefahren, die von Afghanistan } \\
\text { ausgehen, die Unterstützung Tadshikistans bei der Grenzsicherung sowie die Situation in Syrien, zu } \\
\text { der eine Erklärung verabschiedet wird. }\end{array}$ \\
\hline 24.09 .2013 & $\begin{array}{l}\text { Im Rayon Bujnaks (Dagestan) werden bei einem Feuergefecht zwei Untergrundkämpfer von Sicher- } \\
\text { heitskräften getötet. Zwei weitere Untergrundkämpfer werden an der Stadtgrenze von Machatschkala } \\
\text { getötet, nachdem sie das Feuer auf eine Straßenkontrolle eröffnet hatten. }\end{array}$ \\
\hline 27.09 .2013 & Sicherheitskräfte töten in Derbent (Dagestan) fünf Insurgenten, darunter den lokalen Anführer. \\
\hline 28.09 .2013 & $\begin{array}{l}\text { Bei einem Überfall auf eine Polizeistreife in Machatschkala (Dagestan) durch mutmaßliche Unter- } \\
\text { grundkämpfer werden zwei Polizisten getötet und zwei weitere schwer verletzt. }\end{array}$ \\
\hline 30.09 .2013 & Sicherheitskräfte töten im Rayon Baksan (Kabardino-Balkarien) zwei mutmaßliche Untergrundkämpfer. \\
\hline 02.10 .2013 & $\begin{array}{l}\text { Bei Schusswechseln zwischen Sicherheitskräften und Untergrundkämpfern im Rayon Lewaschi } \\
\text { (Dagestan) werden drei Zivilisten, drei Polizisten und vier Insurgenten getötet. Vier Polizisten und } \\
\text { freiwillige Milizhelfer werden verletzt. }\end{array}$ \\
\hline 06.10 & $\begin{array}{l}\text { Präsident Wladimir Putin empfängt auf dem Roten Platz in Moskau die Olympische Flamme für die } \\
\text { XXII Winterolympiade in Sotschi. Diese wurde am Vortag in Athen feierlich dem Organisations- } \\
\text { komitee »Sotschi } 2014 \text { übergeben und wird ab dem Folgetag } 123 \text { Tage lang bis zum Start der Spiele } \\
\text { am } 7 \text {. Februar durch Russland getragen. }\end{array}$ \\
\hline 09.10 .2013 & Unbekannte töten bei einem Überfall in Machatschkala (Dagestan) zwei Verkehrspolizisten. \\
\hline 21.10 .2013 & $\begin{array}{l}\text { ums Leben. } \\
\text { 1). }\end{array}$ \\
\hline 25.10 .2013 & $\begin{array}{l}\text { Sicherheitskräfte töten in Chasawjurt (Dagestan) zwei Untergrundkämpfer, als es bei einer Straßen- } \\
\text { kontrolle zu einem Feuergefecht kommt. Ein Polizist wird verletzt. Im Auto der Getöteten werden } \\
\text { zwei 50-Liter-Fässer mit Sprengstoff sichergestellt. }\end{array}$ \\
\hline 29.10 .2013 & $\begin{array}{l}\text { Bei einem Anti-Terror-Einsatz im Rayon Solskij (Kabardino-Balkarien) werden zwei mutmaßliche } \\
\text { Untergrundkämpfer getötet und mehrere Angehörige der Sicherheitskräfte verletzt. }\end{array}$ \\
\hline 30.10 .2013 & \\
\hline 04.11 .2013 & $\begin{array}{l}\text { Im Rayon Lakskij (Dagestan) werden drei Untergrundkämpfer bei einem Sondereinsatz der Sicher- } \\
\text { heitskräfte getötet. }\end{array}$ \\
\hline 07.11 .2013 & $\begin{array}{l}\text { Tom Weltraumbahnhof Bajkonur startet ein Sojus-Raumschiff zur Internationalen Raumstation mit } \\
\text { rei Kosmonauten und der Olympischen Fackel an Bord. Die Fackel soll am 9. November von zwei } \\
\text { ussischen Kosmonauten in den Weltraum getragen werden und im Februar } 2014 \text { die Olympische } \\
\text { lamme in Sotschi entzünden. }\end{array}$ \\
\hline $\begin{array}{l}07 .- \\
08.11 .2013\end{array}$ & $\begin{array}{l}\text { m Rayon Predgornij unweit von Pjatigorsk (Bezirk Stawropol) werden zwei mutmaßliche Aufstän- } \\
\text { ische getötet, als es bei einer Fahrzeugkontrolle zu einem Feuerwechsel kommt. In ihrem Auto wird } \\
\text { in Sprengsatz gefunden. }\end{array}$ \\
\hline 11.11.2013 & $\begin{array}{l}\text { ine Sojus-Raumkapsel mit drei Astronauten und der Olympischen Fackel an Bord kehrt planmäßig } \\
\text { urück und landet in Kasachstan. }\end{array}$ \\
\hline 16.11.2013 & $\begin{array}{l}\text { In einem Vorort von Machatschkala (Dagestan) werden fünf Untergrundkämpfer getötet. Unter } \\
\text { diesen ist der Ehemann der Selbtmordattentäterin vom 21. Oktober in Wolgograd. }\end{array}$ \\
\hline 19.11.2013 & $\begin{array}{l}\text { Unbekannte töten vor der Geistlichen Verwaltung der Muslime in Machatschkala (Dagestan) zwei } \\
\text { Polizisten. Drei weitere Polizisten werden verletzt. Einer der Täter wird in der Folge erschossen, er } \\
\text { war Mitorganisator des Selbstmordattentates von Wolgograd. }\end{array}$ \\
\hline $\begin{array}{l}\text { 19.-- } \\
\text { 20.11.2013 }\end{array}$ & $\begin{array}{l}\text { Sicherheitskräfte töten im Rayon Baksan (Kabardino-Balkarien) zwei mutmaßliche Untergrund- } \\
\text { kämpfer, die sich der Festnahme zu entziehen versuchten. }\end{array}$ \\
\hline 20.11.2013 & $\begin{array}{l}\text { Im Rahmen einer Spezialoperation werden in Machatschkala (Dagestan) zwei Untergrundkämpfer } \\
\text { getötet, die als Drahtzieher des Selbstmordattentates in Wolgograd bezeichnet werden. }\end{array}$ \\
\hline
\end{tabular}




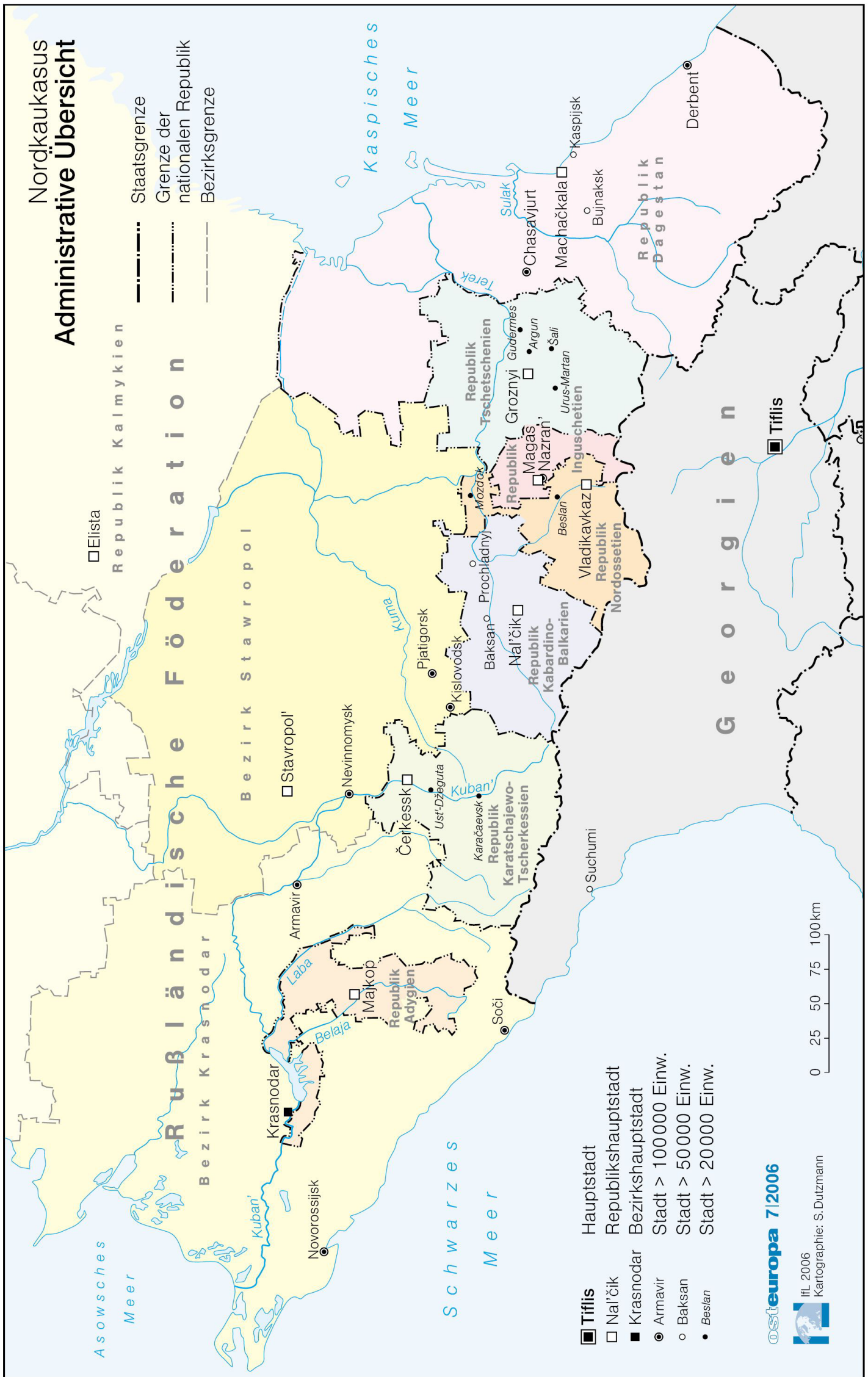




\section{Die Ausgaben für die Olympiade in Sotschi im Vergleich}

Tabelle 1: Olympische Ausgaben und Mehrkosten bei Olympiaden von 1988 - 2014

\begin{tabular}{|c|c|c|c|c|c|c|c|}
\hline \multirow[t]{2}{*}{ Jahr } & \multirow[t]{2}{*}{ Olympiade } & \multirow[t]{2}{*}{ Stadt } & \multirow[t]{2}{*}{ Land } & \multicolumn{3}{|c|}{$\begin{array}{l}\text { Olympische Ausgaben } \\
\text { in Mrd. US\$ (2012) }\end{array}$} & \multirow[t]{2}{*}{ Quelle } \\
\hline & & & & Geplant & $\begin{array}{c}\text { Tatsäch- } \\
\text { lich }\end{array}$ & $\begin{array}{c}\text { Mehr- } \\
\text { ausgaben }\end{array}$ & \\
\hline 1988 & XV Winterspiele & Calgary & Kanada & 0,67 & 1,07 & $+59,0 \%$ & {$[1]$} \\
\hline 1992 & XVI Winterspiele & Albertville & Frankreich & 0,86 & 2,03 & $+135,0 \%$ & {$[1]$} \\
\hline 1992 & XXV Sommerspiele & Barcelona & Spanien & 0,69 & 2,93 & $+325,0 \%$ & [3] \\
\hline 1994 & XVII Winterspiele & Lillehammer & Norwegen & 0,54 & 2,03 & $+277,0 \%$ & {$[1]$} \\
\hline 1996 & XXVI Sommerspiele & Atlanta & USA & 1,64 & 4,05 & $+147,0 \%$ & {$[1]$} \\
\hline 1998 & XVIII Winterspiele & Nagano & Japan & 1,57 & 2,45 & $+56,0 \%$ & {$[1],[9]$} \\
\hline 2000 & XXVII Sommerspiele & Sidney & Australien & 2,36 & 4,48 & $+90,0 \%$ & {$[1],[3]$} \\
\hline 2002 & XIX Winterspiele & Salt Lake City & USA & 1,90 & 2,45 & $+29,0 \%$ & {$[1],[2]$} \\
\hline 2004 & XXVIII Sommerspiele & Athen & Griechenland & 2,00 & 3,20 & $+60,0 \%$ & {$[1]$} \\
\hline \multicolumn{4}{|c|}{ Ausgaben Olympischer Spiele 1988 - 2004} & 4,65 & 13,50 & $+190 \%$ & [3] \\
\hline 2006 & XX Winterspiele & Turin & Italien & 2,40 & 4,37 & $+82,0 \%$ & {$[1],[5]$} \\
\hline 2008 & XXIX Sommerspiele & Peking & China & 5,64 & 5,86 & $+4,0 \%$ & {$[1]$} \\
\hline \multicolumn{4}{|c|}{ Ausgaben Olympischer Spiele 1988 - 2008} & 16,30 & 43,19 & $+165 \%$ & [3] \\
\hline 2010 & XXI Winterspiele & Vancouver & Kanada & 2,10 & 2,45 & $+17,0 \%$ & {$[1]$} \\
\hline \multicolumn{4}{|c|}{ Ausgaben Olympischer Spiele 1988 - 2010} & 2,88 & 6,08 & $+111 \%$ & {$[6],[7]$} \\
\hline 2012 & XXX Sommerspiele & London & England & 3,93 & 15,39 & $+290,0 \%$ & [1],[3] \\
\hline \multicolumn{4}{|c|}{ Olympia-Kosten 1988 - 2012 im Durchschnitt } & 2,02 & 4,06 & $+120,8 \%$ & \\
\hline \multicolumn{4}{|c|}{ Olympische Sommerspiele 1988 - 2012 im Durchschnitt } & 2,71 & 5,98 & $+152,7 \%$ & \\
\hline \multicolumn{4}{|c|}{ Olympische Winterspiele 1988 - 2012 im Durchschnitt } & 1,43 & 2,41 & $+93,6 \%$ & \\
\hline 2014 & XXII Winterspiele & Sotschi & Russland & 5,14 & $* 8,60$ & $+67,5 \%$ & [8],[11] \\
\hline \multicolumn{4}{|c|}{$\begin{array}{l}\text { Gesamte Ausgaben für Sotschi-2014 (Prognose anhand } \\
\text { Preissteigerung) }\end{array}$} & & $* * 13,9$ & $+171,0 \%$ & \\
\hline
\end{tabular}

Anmerkungen: * nach Angaben von 2009, ** Prognose (siehe Original)

Quellen: [1] Flyvbjerg B., Stewart A. (2012): Olympic Proportions: Cost and Cost Overrun at the Olympics 1960-2012, in: Saïd Business School Working Papers, Oxford: University of Oxford, Juni 2012; [2] Olympic Games cost overruns, in: No Games, Februar 2009. <http://nogames.files.wordpress.com/2009/02/costoverruns.pdf>; [3] Jennings W. (2012): Mega-Events and Risk Colonisation. Risk Management and the Olympics, in: CARR. März 2012. <http://soton.academia.edu/WillJennings/Papers/248726/Mega-Events_ and_Ris...>; [4] Nowoshenina O., Iwanowa M., Meremiskaja E. (2007): Sotschi - mesto ne dlja otdycha (Sotschi - kein Ort der Ruhe). In: Gazeta.ru, 5. Juli 2007, <http://sport.gazeta.ru/sport/2007/07/a_1880984.shtml>; [5] Wilkinson T. (2006): Turin Hopes Its Pricey Olympic Makeover Lasts, in: Los Angeles Times, 5. Februar 2006, <http://articles.latimes.com/2006/feb/05/world/fg-turin5>; [6] Wilson B. (2010): Will Vancouver count cost of Olympics?, in: BBC News, 12. Februar 2010, <http://news.bbc.co.uk/2/hi/bus iness/8510177.stm>; [7] 2010 Games in Crisis, in: The Vancouver Sun, 27. September 2006 <http://www.canada.com/vancouver sun/news/story.html?id=01fc5dbe-9e38-4573...>; [8] Postanowlenie Prawitelstva RF ot 8.6.2006 Nr. 357 „O Federalnoj zelevoj programme , Raswitie g. Sotschi kak gornoklimatitscheskogo kurorta (2006-2014 gody) «" (Beschluss der russischen Regierung vom 8. Juni 2006, Nr. 357 „Über das Föderale Zielprogramm , Entwicklung der Stadt Sotschi als bergklimatischer Kurort (2006-2014) "(), unter: <http://www.zakonprost.ru/content/base/part/487742>; [9] Solberg H. (2010): Why major sports events end up more expensive than first planned, Sør-Trøndelag College University, Norway. <http://www.idrett.no/tema/internasjonalt/Documents/idrettsarr.dyrere. pdf>; [10] Taylor A. Blackstone S. 12 Enduring Legacies OfOlympic Host Cities, in: Business Insider, 05.07.2012. <http://www.busi nessinsider.com/the-lasting-legacy-of-the-olympics-2012-6...>;[11] Minregion ozenil raschody na Olimpiadu w Sotschi w 1 trln rublej (Das Ministerium für Regionale Entwicklung schätzt die Ausgaben für die Olympiade in Sotschi auf 1 Billion Rubel), in: Wsgljad, 29. September 2009, <http://www.vz.ru/news/2009/9/29/332019.html>; [12] Samofalowa O. (2013): Rossija wydelilas (Russland sticht hervor), in: Wsgljad, 1. Februar 2013, <http://www.vz.ru/economy/2013/2/1/618531.html>

Berechnung von: Alexander Sokolow, Doktorand am Zentralen Wirtschafts-Mathematischen Institut der Russischen Akademie der Wissenschaften (CEMI RAN), veröffentlicht am 16. August 2012 unter: <http://igpr.ru/articles/zatraty_na_olimpiadu_v_sochi>. 


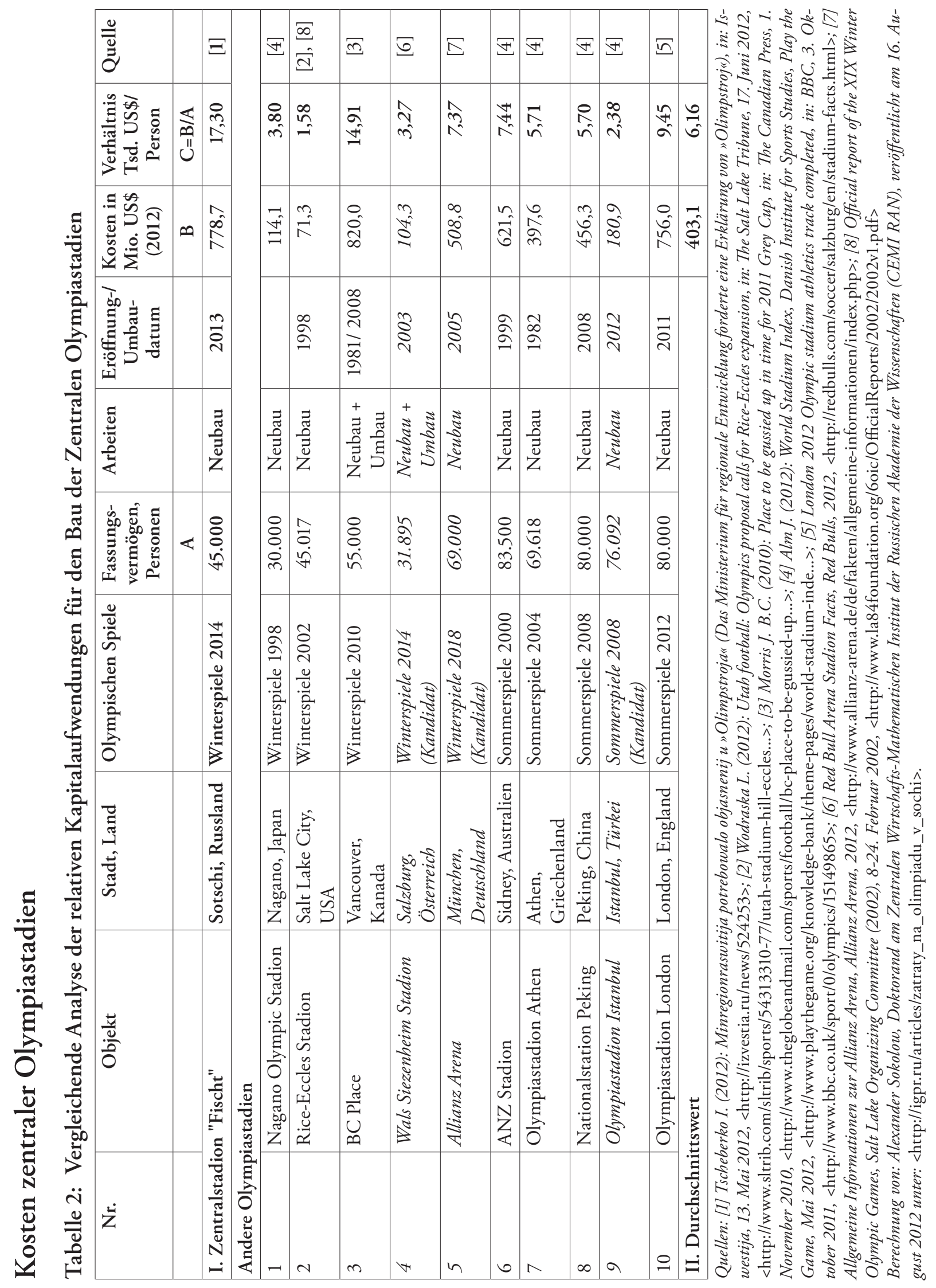




\section{Die Olympiade in Sotschi in russischen Umfragen}

Grafik 1: Haben Sie vor, die Fernsehübertragung der Olympischen Spiele zu sehen?

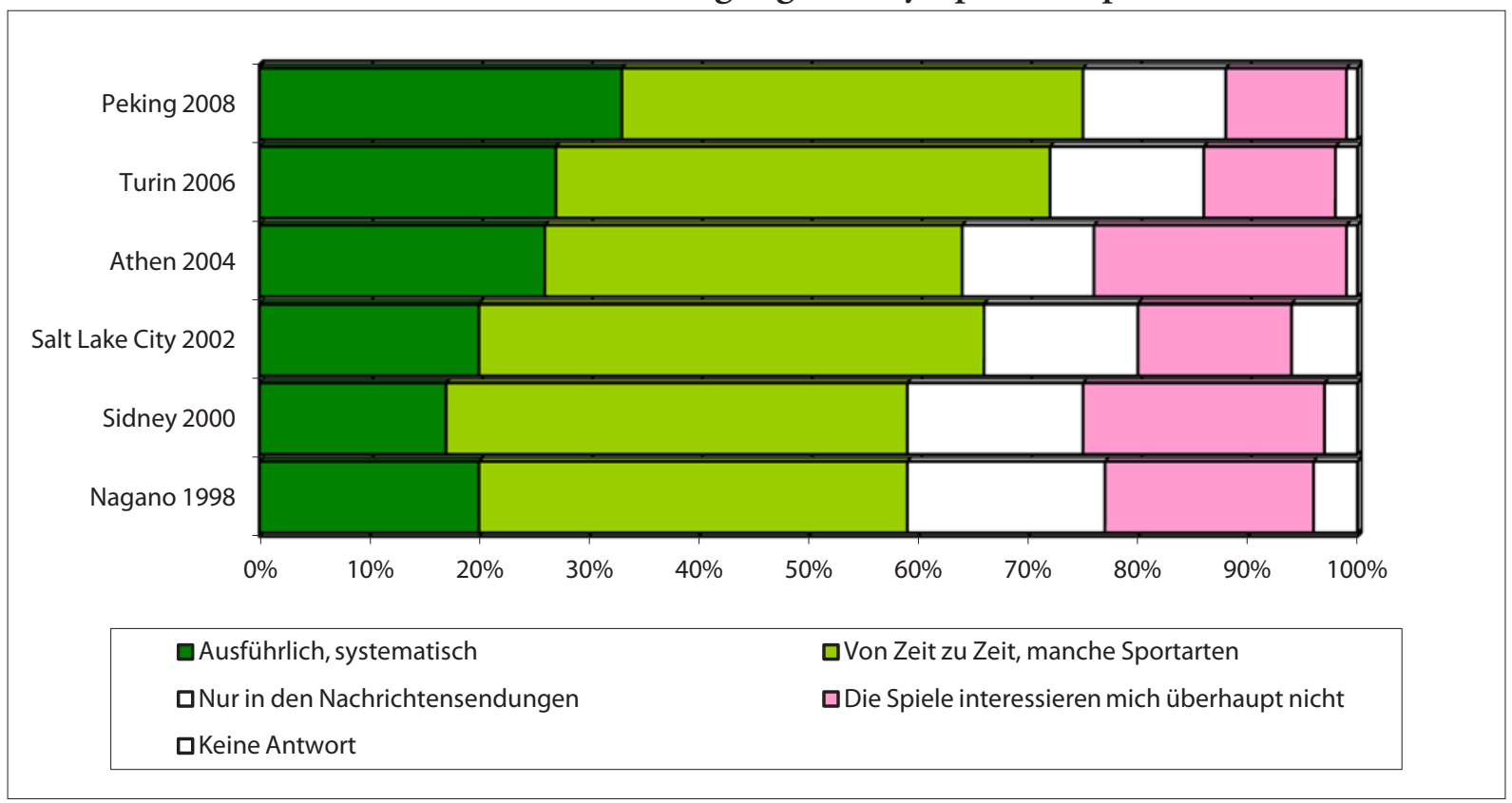

Quelle: Umfragen des Lewada-Zentrums vom 29. August 2008, unter: <http://www.levada.ru./press/2008082900.html>

Tabelle 2: Wie stehen Sie dazu, dass Sotschi den Wettbewerb zur Durchführung der Olympiade 2014 gewonnen hat?

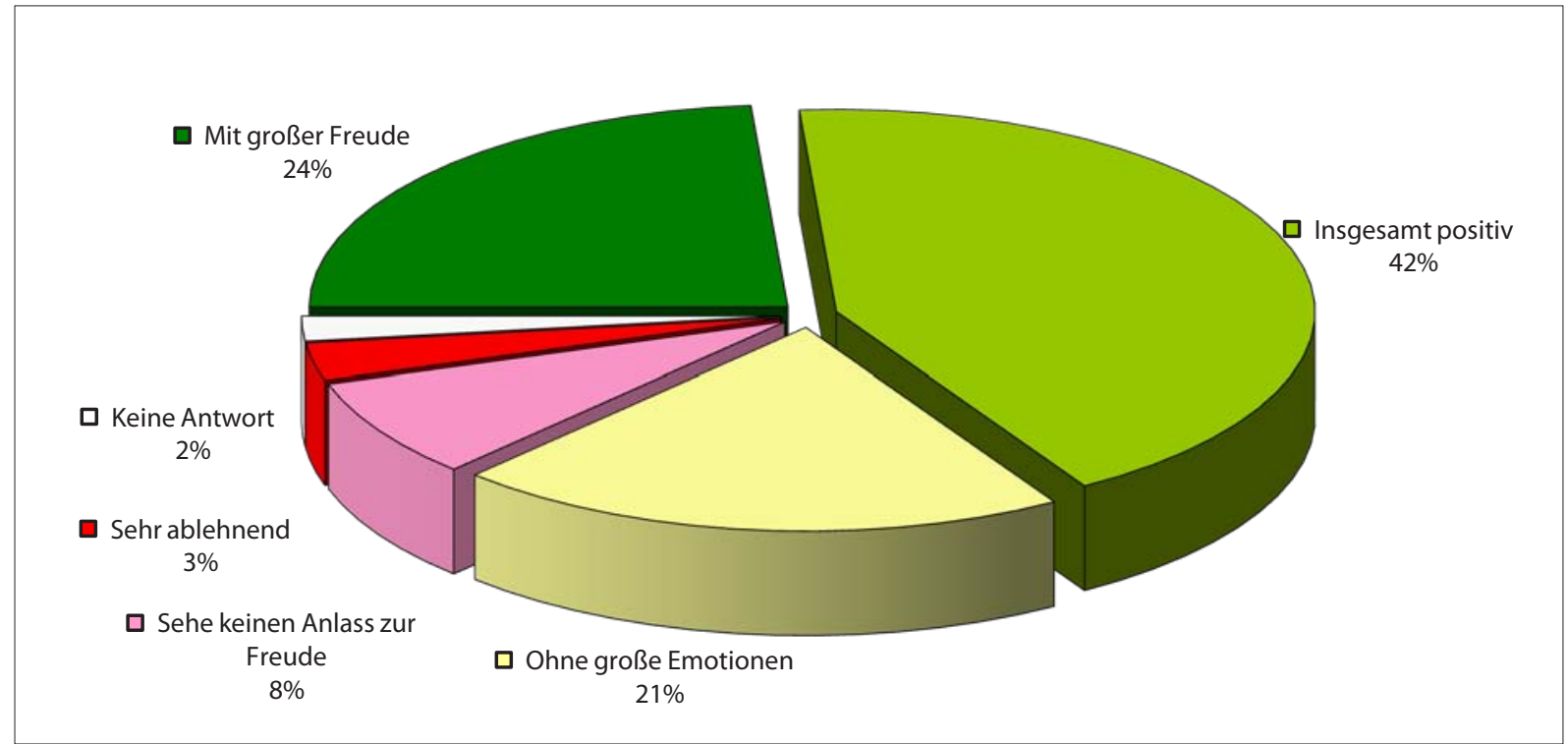

Quelle: Umfragen des Lewada-Zentrums vom 15.-18. April 2011. Veröffentlicht am 4. Mai 2011 unter: <http://www.levada.ru/press/2011050400.html> 
Grafik 3: Kann Russland die Durchführung der Olympischen Winterspiele 2014 in Sotschi würdig organisieren?

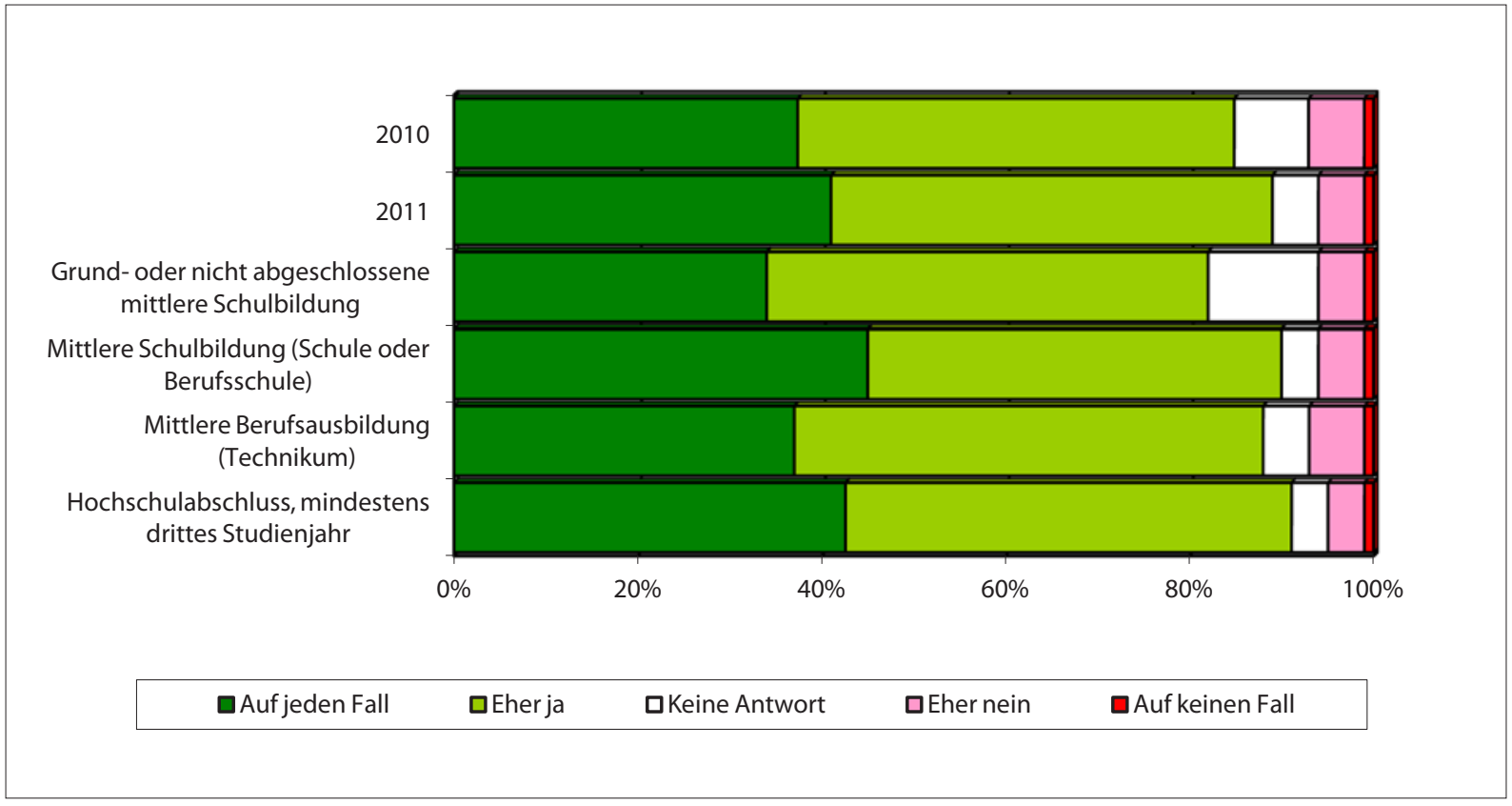

Quelle: Umfragen des WZIOM vom 30. April bis 1. Mai 2011, N = 1600. Veröffentlicht am 11. Mai 2011 unter: $<$ http://old.wciom.ru/novosti/press-vypuski/press-vypusk/single/111607Y>

Grafik 4: Wird es Russland gelingen, den Erfolg der vorherigen Olympia-Gastgeberländer (z. B. Kanada und China) zu wiederholen, deren Mannschaften die meisten Goldmedaillen gewinnen konnten?

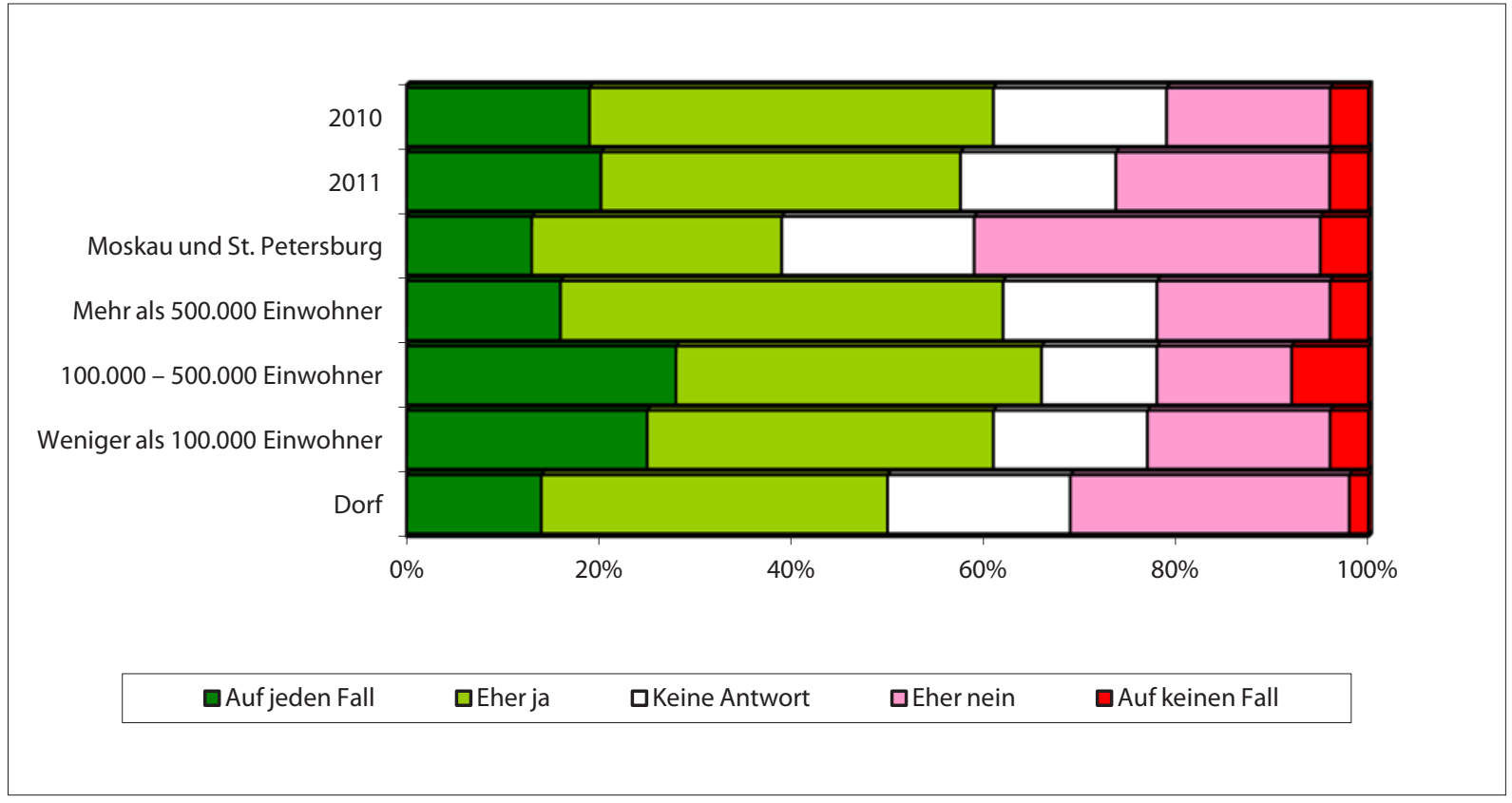

Quelle: Umfragen des WZIOM vom 30. April bis 1. Mai 2011, $N=1600$. Veröffentlicht am 11. Mai 2011 unter: $<$ http://old.wciom.ru/novosti/press-vypuski/press-vypusk/single/111607Y> 
Grafik 5: Sind Sie auf die Olympischen Winterspiele 2014 in Sotschi und die Fußballweltmeisterschaft 2018 in Russland stolz?

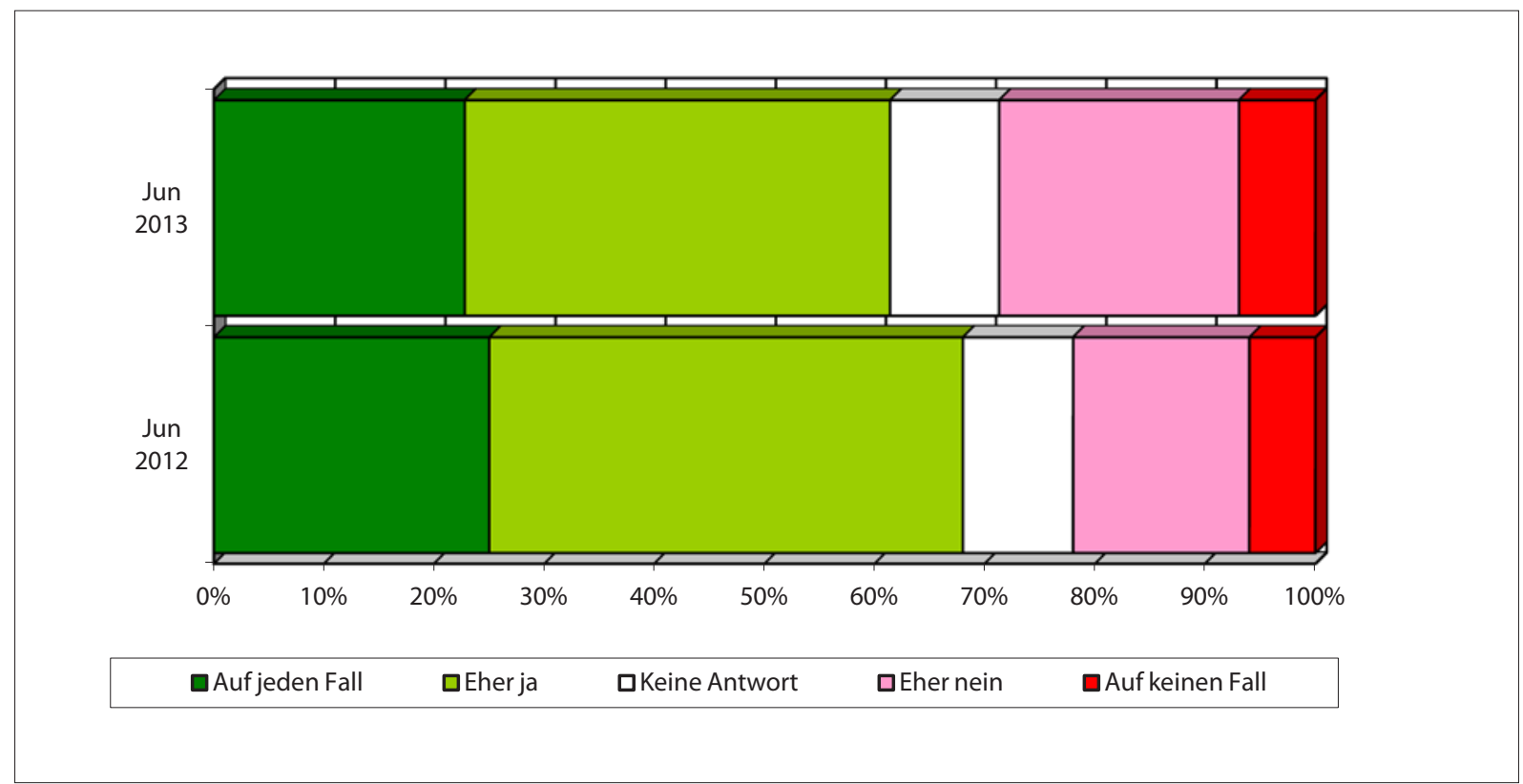

Quelle: Umfragen des Lewada-Zentrums vom 6.-10. Juni 2013, $N=1601$. Veröffentlicht am 27. Juni 2013, unter: $<$ http://www.levada.ru/print/27-06-2013/obshchestvennoe-mnenie-ob-izderzhkakh-olimpiady>

Grafik 6: Werden die Gelder, die für die Vorbereitungen der Olympiade in Sotschi aus dem Föderalhaushalt bereitgestellt werden, effektiv verwendet?

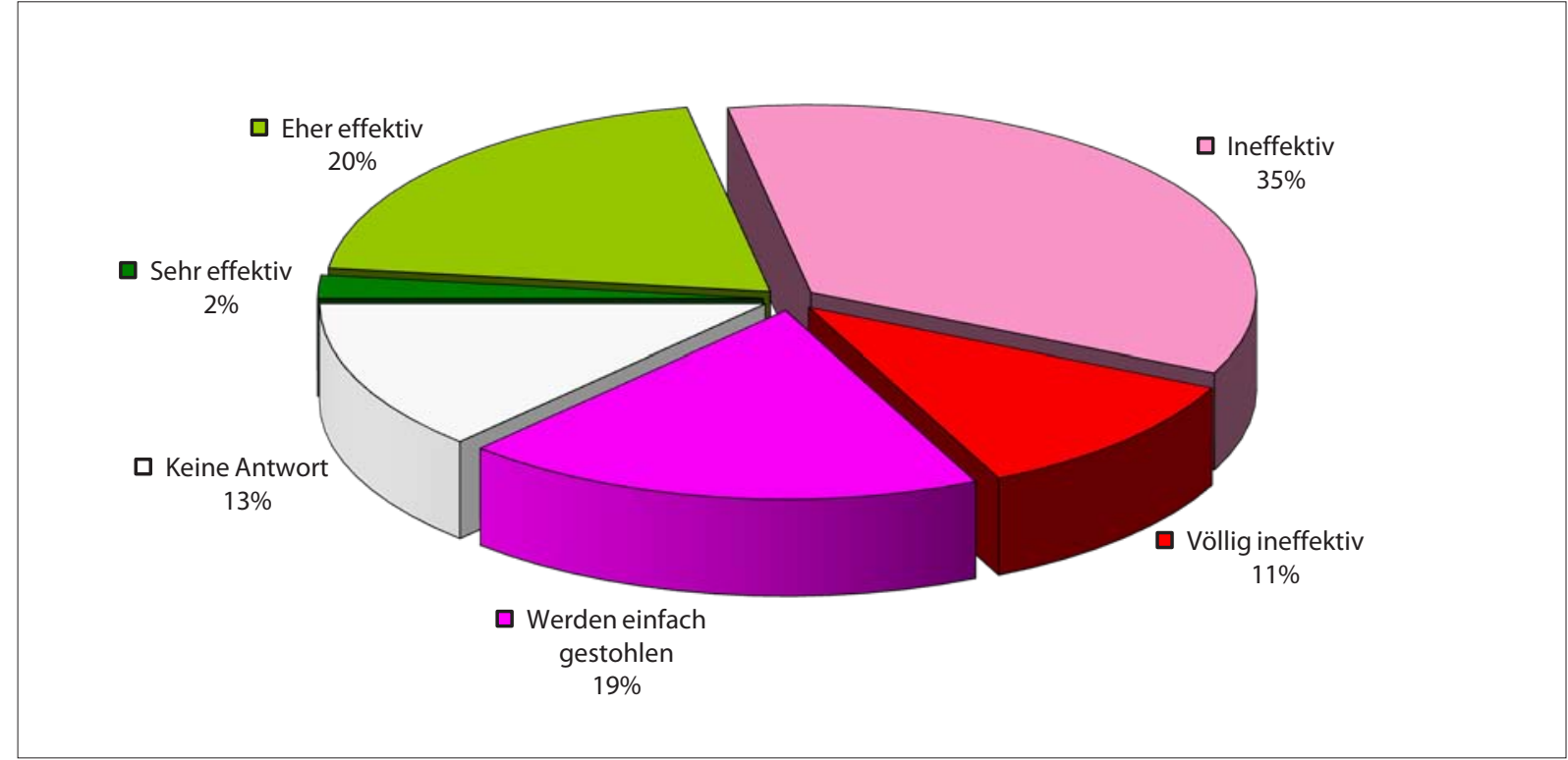

Quelle: Umfragen des Lewada-Zentrums vom 6.-10. Juni 2013, $N=1601$. Veröffentlicht am 27. Juni 2013, unter: <http://www.levada.ru/print/27-06-2013/obshchestvennoe-mnenie-ob-izderzhkakh-olimpiady> 
Grafik 7: Werden sich die Mittel, die Russland in die Vorbereitung solcher Imageprojekte wie die Olympischen Winterspiele 2014 in Sotschi und die Fußballweltmeisterschaft 2018 investiert, wirtschaftlich rechnen?

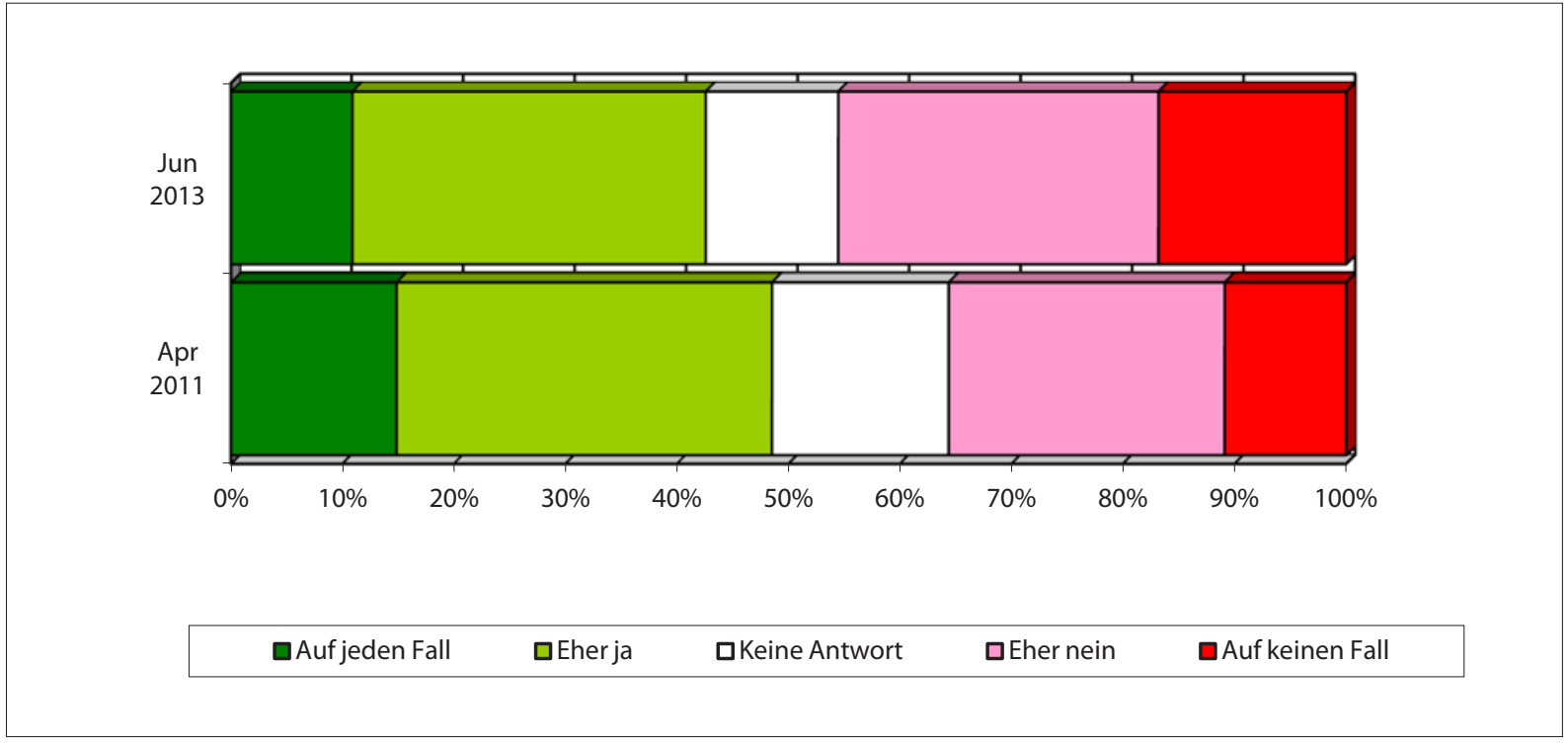

Quelle: Umfragen des Lewada-Zentrums vom 6.-10. Juni 2013, $N=1601$. Veröffentlicht am 27. Juni 2013, unter: <http://www.levada.ru/print/27-06-2013/obshchestvennoe-mnenie-ob-izderzhkakh-olimpiady>

Grafik 8: Sollte Russland Ihrer Meinung nach für solche Imageprojekte große Mittel einsetzen?

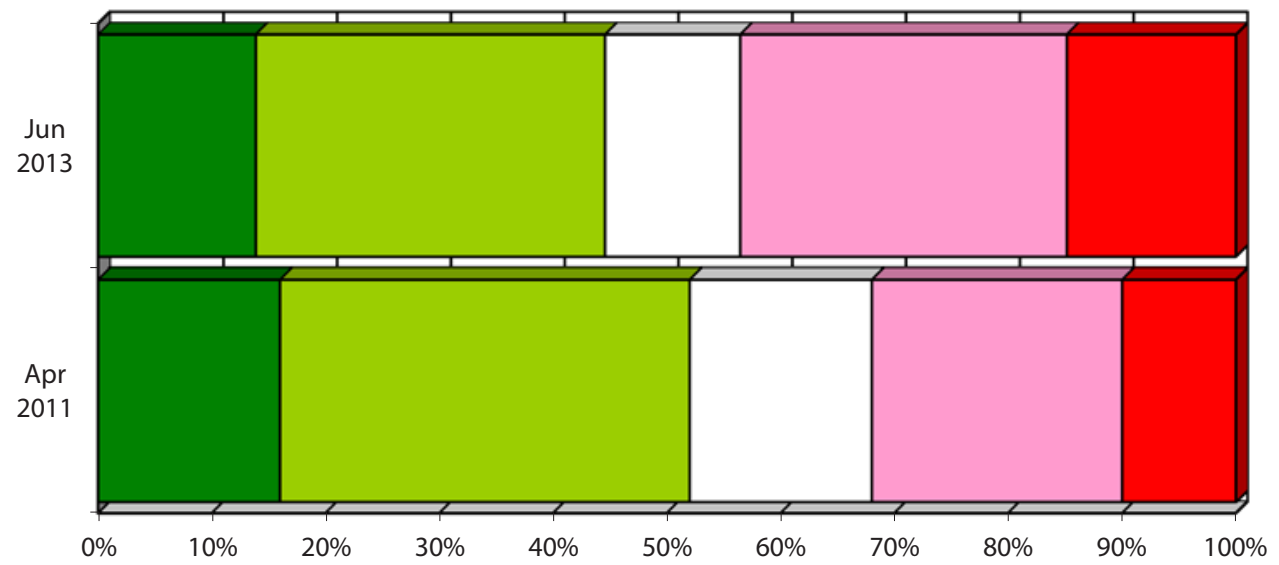

$\square$ Aufjeden Fall $\quad$ Eherja

口Keine Antwort

口Eher nein

$\square$ Auf keinen Fall

Quelle: Umfragen des Lewada-Zentrums vom 6.-10. Juni 2013, $N=1601$. Veröffentlicht am 27. Juni 2013, unter: $<$ http://www.levada.ru/print/27-06-2013/obshchestvennoe-mnenie-ob-izderzhkakh-olimpiady> 
Grafik 9: Wie stehen Sie zur Durchführung der Olympischen Winterspiele 2014 in Sotschi?

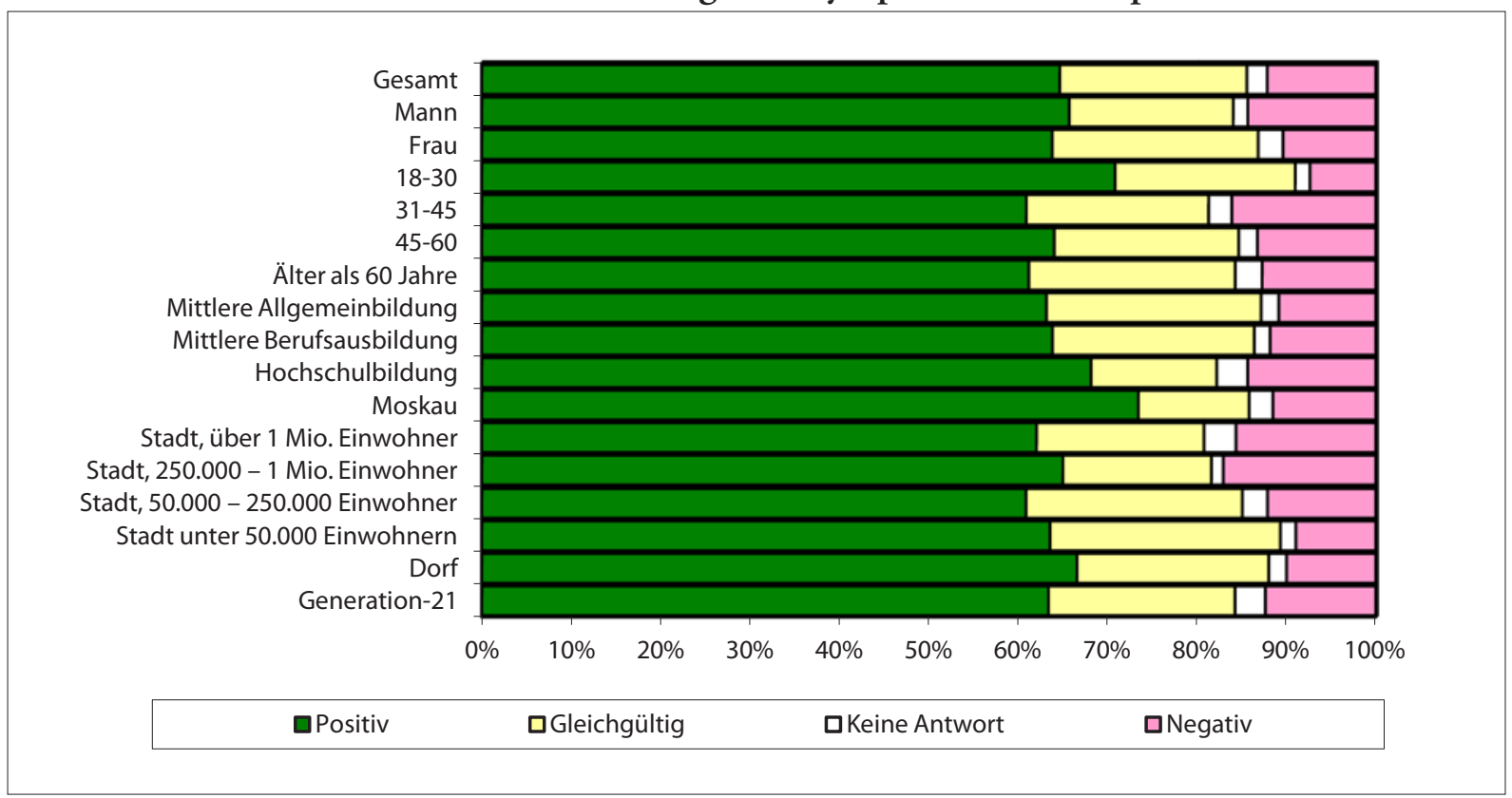

Quelle: Umfragen der Stiftung Öffentliche Meinung vom 12.-13. Oktober 2013, N=1500. Veröffentlicht am 28. Oktober 2013 unter: <http://fom.ru/obshchestvo/11159>.

Grafik 10: Wirken sich Vorbereitungen auf die Olympischen Winterspiele 2014 in Sotschi auf die wirtschaftliche Entwicklung Russlands aus? Wenn ja, wie?

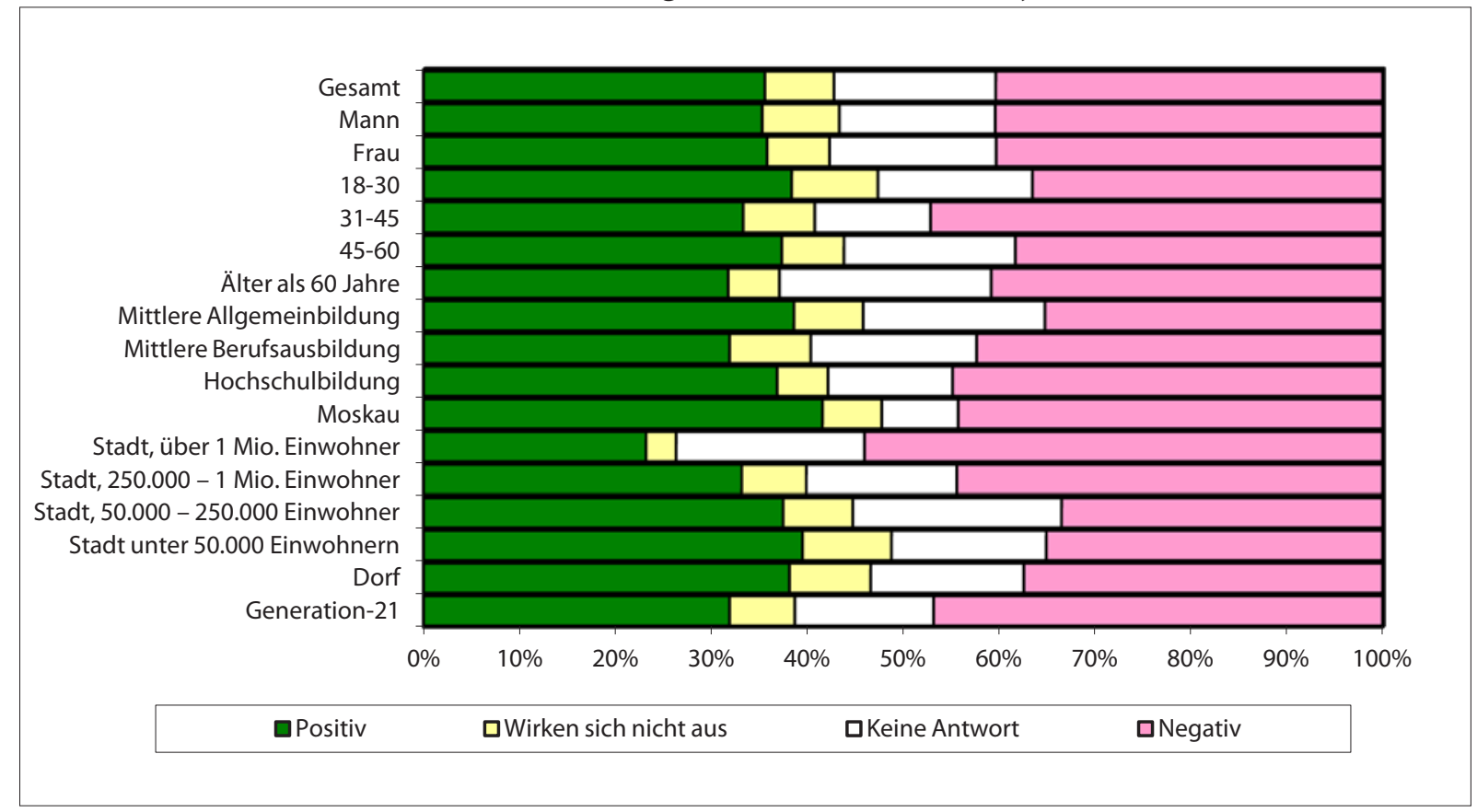

Quelle: Umfragen der Stiftung Öffentliche Meinung vom 12.-13. Oktober 2013, N=1500. Veröffentlicht am 28. Oktober 2013 unter: $<$ http://fom.ru/obshchestvo/11159>. 
Grafik 11: Wird für die Olympischen Winterspiele 2014 zu viel, zu wenig oder gerade ausreichend investiert?

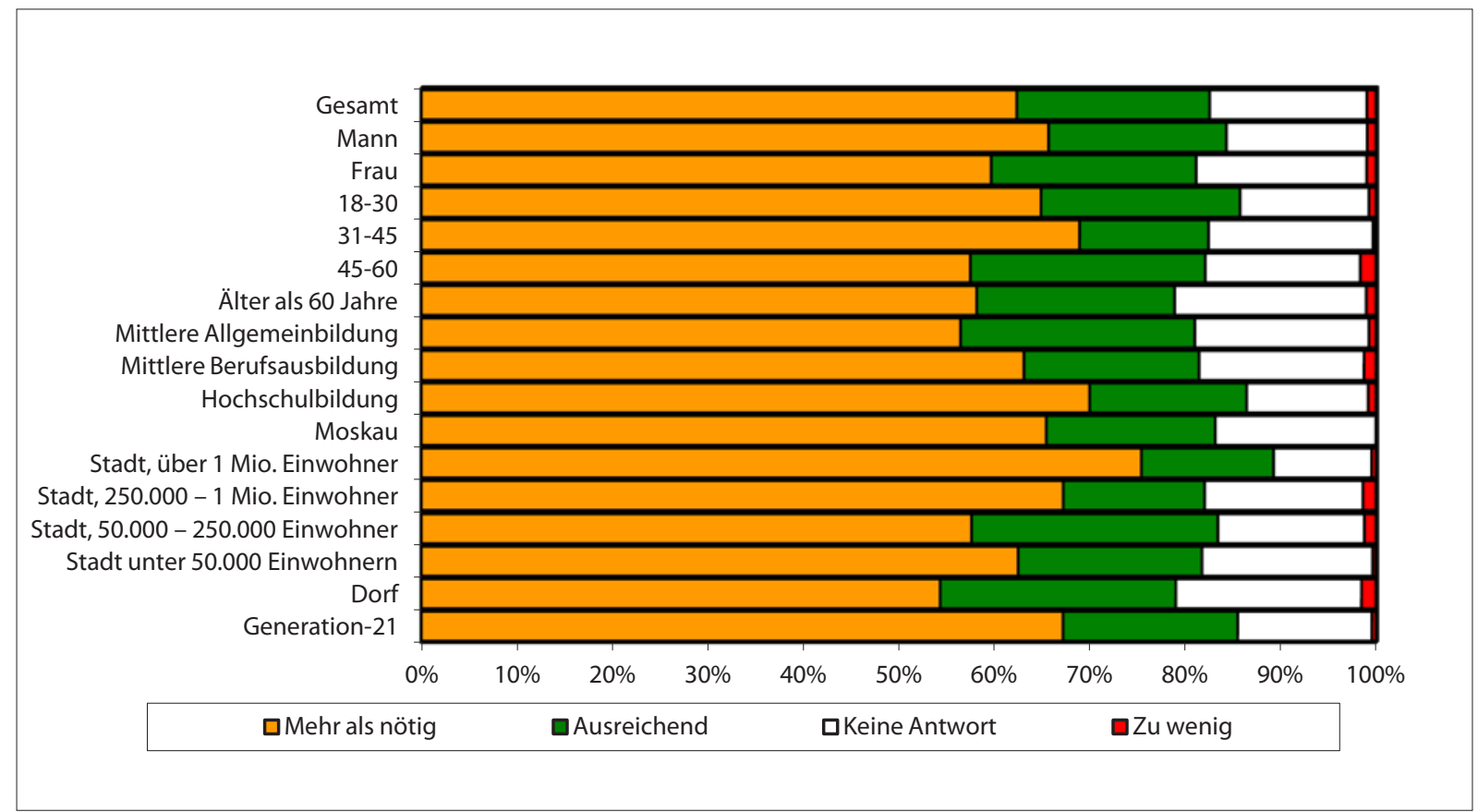

Quelle: Umfragen der Stiftung Öffentliche Meinung vom 12.-13. Oktober 2013, N=1500. Veröffentlicht am 28. Oktober 2013 unter: <http://fom.ru/obshchestvo/11159>.

Grafik 12: Sind bei den bevorstehenden Olympischen Winterspielen in Sotschi folgende Ereignisse möglich? (Mehrere Antwortmöglichkeiten)

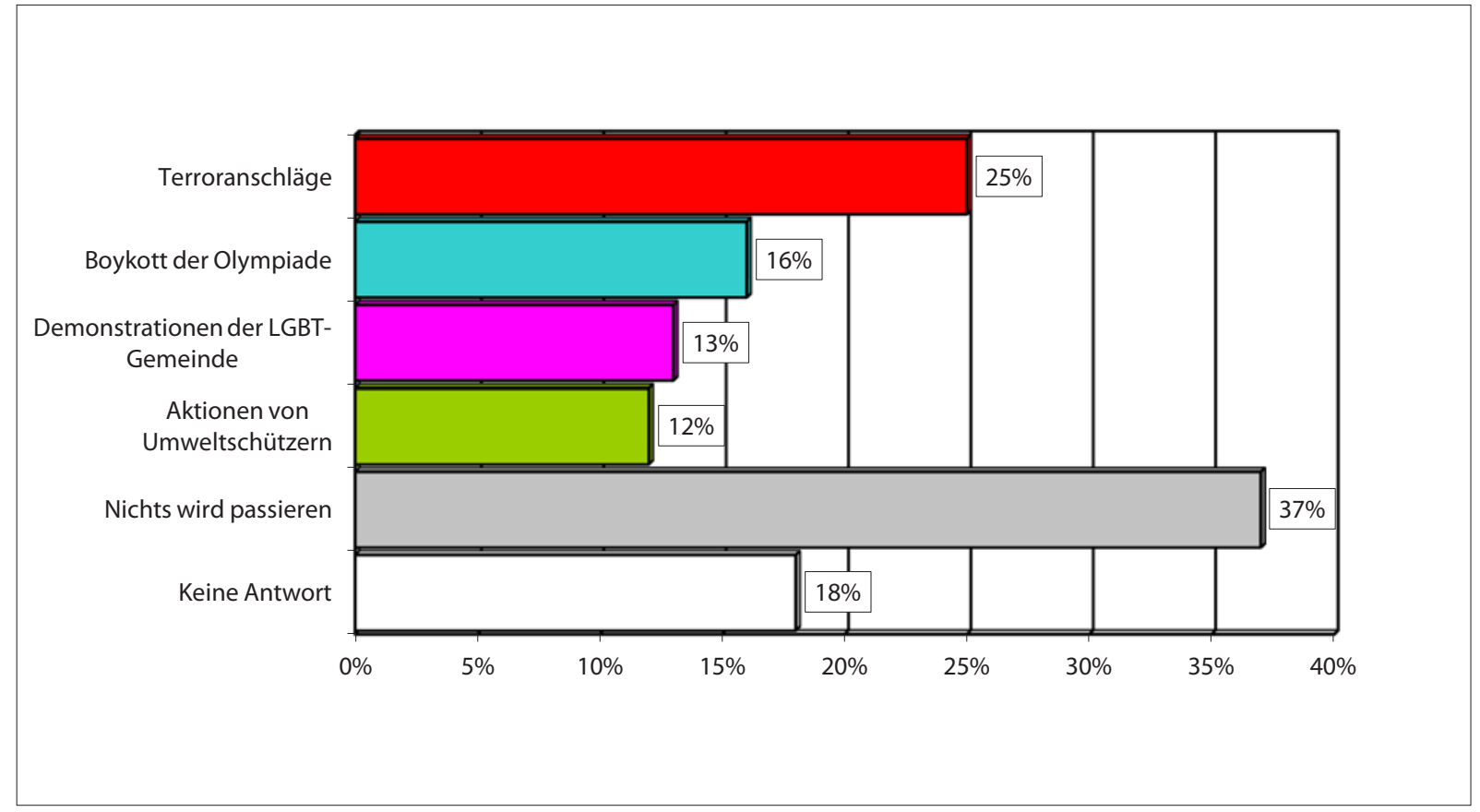

Quelle: Umfragen des Lewada-Zentrums vom 25.-28. Oktober 2013, $N=1603$. Veröffentlicht am 26. November 2013 unter: <http://www.levada.ru/print/26-11-2013/vozmozhnye-sobytiya-na-zimnei-olimpiade-v-sochi> 


\section{Verdammte Winterspiele}

\section{„Geknebelte Olympische Spiele»}

Die Vorbereitung der Winterspiele in Sotschi hatte eine Unterdrückung der Zivilgesellschaft, Verfolgung von Aktivisten, Beeinträchtigung der Rechte der lokalen Bevölkerung, Einschränkung der Arbeit von Journalisten, ein Totschweigen der Willkür von Polizisten und Vernichtung der Natur zur Folge. Arbeitsmigranten, die bei der Errichtung des Olympischen Dorfs und der Infrastruktur in Sotschi eingesetzt wurden, mussten unter menschenunwürdigen Lebensbedingungen hausen. Gastarbeiter wurden wie Sklaven behandelt und sollen gefoltert worden sein. Lokale Menschenrechtler und Umweltaktivisten werden bedroht, ihre Wohnungen durchsucht. Gegen die letzten unabhängigen Medien üben regionale Behörden massiven Druck aus. Das Recht auf Freizügigkeit, Versammlungs- und Pressefreiheit werden während der Winterspiele in Sotschi stark eingeschränkt sein. Aufnahmen und Videos mit Handys für Journalisten der Printmedien strikt verboten. Besucher dürfen keine professionellen Video- und Spiegelreflex-Kameras benutzen.

So empört sich der Journalist Jewgenij Titow, wie »freie schöne Olympische Spiele zu einem geheimen Ereignis eines altersschwächelnden Präsidenten« geworden sind: »die Sicherheitsorgane haben eine verzerrte Sicherheitsformel im Kopf: Geschlossenheit plus Totschweigen plus Unterdrückung gleich Sicherheit der Olympischen Spiele in Sotschi. Das Image der Olympischen Spiele scheint wichtiger zu werden, als die tatsächlichen Olympischen Spiele. Ein Sportereignis des 21. Jahrhunderts wird nach Maßgabe der Vorstellungen von 1937 durchgeführt.«

"Geknebelte Olympiade« von Jewgenij Titow, 11. November 2013; <http://estitov.livejournal.com/384822.html>

\section{Hauptrisiko in Sotschi 2014}

Das Hauptproblem der Winterspiele in Sotschi ist ganz und gar nicht der Terrorismus, sondern die fürchterliche Qualität der Bauarbeiten. Den Terrorismus wird Putin schon bekämpfen. Er muss nur ausreichend Tschekisten und "Extremismusbekämfer« nach Sotschi schicken sowie Mitarbeiter von Gazprom und Russischer Bahn auf die Tribüne setzten, den Fan-Pass einführen und den Einwohnern verbieten, auszugehen und Auto zu fahren. Auf der Baustelle ist alles viel komplizierter«, schreibt Boris Nemzow. Der oppositionelle Politiker weist darauf hin, dass Anfang November schon das dritte Mal ein Sturm das System neuer Uferbefestigungen aus Beton im Imeretinskij-Tal verwüstet hat. Das Objekt ist für die ganze Infrastruktur der Stadt und als Schutz der Stadien und Hotels gegen das Meer und Unterspülungen lebenswichtig. Nach Angaben von Nemzow wurden in Sotschi neue Gebäude auf dem subtropischen Sumpf im Erdbebengebiet ohne richtige Experten-Gutachten gebaut. Die Bauarbeiten hat die Firma »Inschtransstroj« durchgeführt, die Arkadij Rotenberg gehört, einem engen Freund von Wladimir Putin und dessen ehemaligen Judo-Trainingspartner. "Uns bleibt zu hoffen, dass niemand während und nach den Winterspielen in Sotschi verletzt wird..." "Hauptrisiko der Olympischen Spiele in Sotschi« von Boris Nemzow, 3. November 2013; <http://besttoday.ru/subjects/1773. html\#60127>

\section{Sotschi 2014: nur für den Export!}

Der Skandal mit den Journalisten aus Norwegen, die trotz offizieller Akkreditierung im November 2013 festgenommen und bedroht wurden, war nur ein weiteres Zeichen im Gesamtbild des kommenden Ereignisses in Sotschi. Schon jetzt ist klar, dass Putin die Winterspiele 2014 ausschließlich für die Außenwelt veranstaltet. Die einheimische Bevölkerung wird und ist bereits von Sotschi ferngehalten. Die Olympischen Spiele werden als Schaufenster für den Export des neuen Russlandbildes instrumentalisiert. Die Russische Regierung kann sich aber mit diesem Konzept bis auf die Knochen blamieren, da längst bekannt ist, dass die Aufmerksamkeit der Welt genau auf diejenigen Dinge gerichtet ist, welche der Staat zu verbergen versucht.

"Olympische Spiele für Export« von Oleg Kosyrew, 6. November 2013; <http://oleg-kozyrev.livejournal.com/4681067.html>

\section{Olympische Spiele, die auf die Nerven gehen}

Nach dreißig Jahren werden wieder Olympische Spiele in Russland stattfinden. Die Russen hätten sich darüber freuen und stolz auf ihr Land sein können. Es herrschen aber gespaltene Gefühle in Bezug auf das Weltsportereignis Nummer Eins. Russische Psychologen sagen, dass die Olympischen Spiele in Sotschi den russischen Bürgern zunehmend auf die Nerven gehen, weil die Nachrichten über ein ständig steigendes Budget der Winterspiele und die Konzentration öffentlicher Ressourcen für das Projekt stark mit dem prekären Zustand der Infrastruktur kontrastieren. Während mehr als ein Drittel der Bevölkerung Russlands laut Rosstat ohne Warmwasser leben, erreicht die Olympische Flamme zum ersten Mal in der Geschichte der Olympischen Spiele den Nordpol und besucht die Internationale Weltraumstation, selbstverständlich auf Kosten der Steuerzahler. 
Ein anderer Grund für die ablehnenden Reaktion ist auf die Kluft zwischen den Interessen der herrschenden Eliten und der Bürgern zurückzuführen. Mit dem Image-Projekt Sotschi 2014 versucht die Staatsführung, das Russlandbild in der Welt zu verbessern und den verlorenen Ruf der Supermacht wiederzubeleben. Die Bürger beschäftigen sich aber hauptsächlich mit materiellen Sorgen und kämpfen ums Überleben. Die Richtigkeit der Entscheidungen der Regierung wird aber von der überwiegenden Zahl der Russen nur deshalb nicht in Frage gestellt, weil sie nicht mehr an Gerechtigkeit als solche glauben. Der fehlende Glaube an die Werteordnung und der Zynismus, die zur Norm in der Gesellschaft geworden sind, führen zu dem allgemeinen Mißtrauen. In einer solchen Situation werden selbst äußerst positive Ereignisse, wie etwa Olympische Spiele, oft als eigennützige Projekte von Beamten und Wirtschaftseliten wahrgenommen.

"Olympische Spiele, die auf Nerven gehen. Wie sehen es die Psychologen?" von Walerij Sawelijew, 19. Oktober 2013; <http://vg-saveliev.livejournal.com/512027.html>

\section{Heben die Olympischen Spiele die Amnestie auf?}

Wladimir Putin beauftragte den Menschenrechtsrat beim Präsidenten, für die Amnestie anlässlich des 20. Jahrestags der russischen Verfassung eine Liste von Gefangenen vorzubereiten. Die Amnestie soll am 12. Dezember 2013 verkündet werden. Allerdings bleibt zu wenig Zeit für eine Verabschiedung des Amnestie-Gesetzes durch die Staatsduma sowie seine Umsetzung durch die Strafvollzugsbehörde (FSIN). Der Grund zur Verzögerung mit der Amnestie könnte an der Vorbereitung für die Winterspiele in Sotschi liegen, meint der Journalist Irek Murtasin von der Nowaja Gaseta.

Russland hat bereits große Erfahrungen mit der Durchführung von Olympischen Spielen gemacht. Bereits im Frühjahr 1980 wurden beispiellose Sicherheitsmaßnahmen in der ganzen Sowjetunion ergriffen. Miliz und KGB wurden intensiv in den Regionen eingesetzt. Verdächtige wurden unter Kontrolle gestellt. In Moskau fand eine totale Säuberung statt. Tausende Obdachlose und »unerwünschte Elemente« wurden aus der Hauptstadt hinter den 101. Kilometer verbannt.

Ähnliche Aktionen laufen momentan im Süden Russlands. Die Sicherheit bei den Winterspielen in Sotschi hat für Putin höchste Priorität. Wenn die Amnestie zum 20. Jahrestag der russischen Verfassung doch durchgesetzt sein wird, dürften die Gefangengen mit der Freilassung erst nach den Winterspielen rechnen können.

"Heben die Olympische Spiele die Amnestie auf?" von Irek Murtasin, 28. November 2013; <http://irek-murtazin.livejour nal.com/1076598.html>

\section{Sotschi im Schnelldurchgang: Prestige, Selbstvergewisserung, Korruption, Viktor Jerofejew und der Weißmeerkanal}

Jens Siegert, Moskau

$\mathrm{D}$ ie Olympischen Winterspiele in Sotschi beginnen in zwei Monaten, also sehr bald. Und dieser Blog hat sie noch nicht zum Thema gehabt. Wohl ein Versäumnis. Wenn ich so nachdenke, liegt das aber daran, dass mir dazu eher zu viel einfällt als zu wenig. Man könnte über Sotschi und die Korruption schreiben. Über Sotschi und den Nordkaukasus. Über Sotschi, Abchasien und Georgien. Über Sotschi und die Umwelt. Über Sotschi und den Umgang mit der eigenen Bevölkerung. Über Sotschi als Sicherheitsproblem. Über Sotschi als nationales und persönliches Prestigeprojekt. Über Sot- schi und den Polizeistaat. Über Sotschi als nationale Selbstversicherung. Über Sotschi, Russland und Doping. Und selbstverständlich auch über Sport.

Also im Schnelldurchgang: Offiziell rund $40 \mathrm{Milli}-$ arden Euro kosten die Sotschi-Spiele inzwischen. Das ist gut sechsmal mehr als ihre Vorgänger in Vancouver 2010 (was in Kanada ziemlich kritisch diskutiert wurde). Es gibt wohl niemanden in Russland, der oder die nicht davon überzeugt ist, dass ein erheblicher Teil dieses Geldes geklaut worden ist. Aber es geht ums nationale Prestige. Und geklaut wird überall im russischen 
Staat. Deshalb schaut man erstmal weg, zumindest bis der Medaillenspiegel feststeht (und Russland, so natürlich die große Hoffnung bei Führung und Volk, ganz oben zu finden ist).

Der Nordkaukasus bleibt unruhig (bis auf die mit viel Blut und Leid erkaufte Ruhe in Tschetschenien). Die nordkaukasischen Regionalpotentaten haben, zumindest bis Sotschi, eine carte blanche. Hauptsache es bleibt ruhig. Ansonsten gibt es in Russlands Süden Russlands Polizei, Geheimdienst, Armee, noch mehr Polizei, noch mehr Geheimdienst und noch mehr Armee. Alles, was auch nur ansatzweise verdächtig ist, wird kontrolliert und reglementiert. Sotschi wird eine Festung sein, wie es bisher nur G8- oder G20-Tagungsorte waren. Hoffentlich (und ich hoffe das wirklich und selbstverständlich aus ganzem Herzen!) geht alles gut.

Ob deswegen aber alle paar Tage (ausländische) Journalisten drangsaliert werden müssen, regionale Umweltaktivisten festgesetzt oder ins Ausland getrieben, und die 30 armen Greenpeace-Aktivisten (als Warnung für alle, die auf die Idee kommen könnten, die weltweite Olympiaaufmerksamkeit für ihre auch noch so berechtigten Anliegen nützen zu wollen) zu hohen Haftstrafen verurteilt werden müssen, wage ich zu bezweifeln, fürchte aber, damit hier im Land in der Minderheit zu sein. Für Sotschi ist (fast) nichts zu teuer.

Georgien und Abchasien vergessen wir während der Olympischen Spiele lieber. Das ist zu verwickelt und stört, seit Putins persönlicher Lieblingsfeind Michail Saakaschwili nicht mehr georgischer Präsident ist, nicht wirklich.

$(\mathrm{Zu})$ Viele Doping-Disqualifizierungen russischer Athleten könnten die Spiele natürlich verderben. Bei fast allen großen Sportereignissen der jüngeren Vergangenheit waren russische Sportler überdurchschnittlich unter den Dopingsündern vertreten. Mitte November entzog die internationale Antidopingagentur WADA dem nationalen russischen Doping-Labor in Moskau die Zulassung. Da fehlte wohl das Vertrauen in die notwendige Unabhängigkeit und Objektivität. Das IOC erklärte aber flugs, die Dopingkontrollen während der Spiele seien auch so gesichert. Doch das Gastgeberland bloßstellen? Das passt weder zum IOC, noch zu anderen internationalen Sportverbänden. Und in Russland selbst glauben ohnehin die meisten, dass Dopingkontrollen nur eine (natürlich westliche - immer dieser Rechtstaat!) Abart des unfairen Wettkampfs sind, nicht das Doping selbst. Hier treffen sich Volk und Führung erneut in der zynischen (aber vielleicht gar nicht so falschen) Annahme, dass ohnehin alle dopen.

Das war der Schnelldurchlauf. Nun komme ich zum Wesentlichen. Sotschi war und ist als Krone der Putinschen Konsolidierung des russischen Staates gedacht.
Das wiedererstarkte (Kremldiktion: "von den Knien wieder auferstandene») Russland zeigt sich und der Welt seine wiedergewonnene Kraft und Herrlichkeit. Und es zeigt sie sich selbst. Das darf der tief verunsicherten (und gespaltenen) Nation nicht misslingen.

Einen Vorgeschmack gibt schon der Fackellauf. Die Fackel, mit der die olympische Flamme seit Wochen kreuz und quer durchs Land getragen wird, ist eine Spezialanfertigung der russischen Rüstungsindustrie, des Stolz-, Herz-, und Reststücks russischer Innovationskraft. Viele Millionen Rubel hat die Entwicklung gekostet. In den sozialen Netzwerken wird, mal höhnisch, mal bangend, gezählt, wie oft sie schon ausgegangen ist (Schon Ende Oktober, in St. Petersburg, war man bei $30 \mathrm{mal}$ angekommen). Nun war die Fackel schon am Nordpol und im westlichen Kaliningrad, im Fernen Osten und im All. Auf den 5642 Meter hohen Elbrus, den höchsten Berg Europas, wird sie zum Schluss erneut in dünne Luft getragen, bevor mit ihr im nahen Sotschi, dem südlichsten Punkt Russlands, das olympische Feuer entzündet wird. Das war, natürlich, die längste Fackeltour der olympischen Geschichte. Ein wenig erinnert das an einen Hund, der sein Gelände markiert, um allen Konkurrenten zu zeigen, von wo sie sich gefälligst rauszuhalten haben.

Das Hohelied auf die Staatsmacht mit ihrem Führungsmann Wladimir Putin, die Russland wieder zur "Siegernation" gemacht hat (siehe auch meinen Blogeintrag zur »einfachen Erinnerung « <http://russland.boell blog.org/2013/10/30/russische-erinnerung-bisher-liebereinfach-als-kompliziert/>), kommt bisher noch ein wenig heiser herüber. Aber bisher gibt es die Siege von Sotschi ja auch noch nicht. Bang wird es, sollten sie ausbleiben.

Einen in jeder Hinsicht bemerkenswerten Versuch hat dieser Tage der auch in Deutschland bekannte, vielseits geschätzte und als FAZ-Kolumnist tätige Schriftsteller Viktor Jerofejew geliefert. In der gemäßigt kremlkritischen Tageszeitung »Kommersant« sang er ein Lied auf den »kräftigen Hausherrn", der die Spiele ermöglicht, ja durch seinen Willen erst möglich gemacht habe. Wer damit gemeint ist, wird nicht gesagt, versteht sich aber von selbst. Hier ein paar ausgewählte Zitate:

"Als mir der Bürgermeister von Sotschi, Anatolij Pachomow, ein Mann mit willensstarkem Blick, mit Stolz und Zuneigung die olympischen Objekte kosmischen Maßstabs zeigte, glaubte ich meinen Augen nicht... Wir bekommen am Schwarzen Meer die Olympiastadt Sotschi, umgewandelt, nicht wiederzuerkennen..."

"Die Sonne Russlands, sage ich dem Bürgermeister mit einem leichten Lächeln, geht nun in Sotschi auf..."

"Ja, Sotschi dient unserer Europäisierung. Und stellen Sie sich vor... was die Sportler und Touristen denken werden, wenn sie nach Sotschi kommen? Sie sagen: Man hat 
uns gesagt, Russland sei ein Kühlschrank. Aber Russland, das sind Palmen und Bambusgewächse! Riviera!"

"Wissen Sie, ich habe vor zehn Jahren eine Autobiographie mit dem Titel "Der gute Stalin" geschrieben... Der schlechte Stalin, das ist 1937. Aber der gute erfreut das Volk, baut Staudämme, straft, aber nicht millionenfach. Und nun hat jemand in der Art der guten Stalins sich der Olympiade in Sotschi angenommen und die Sache bis zu Ende gebracht."

"Wir haben nicht das schlechteste Regime... Wenn wir eine Revolution machen, dann erwartet uns eine neue Katastrophe... Ich sage: Danke den kräftigen Bauleuten und Bauherren in Sotschi! Erfolg den Sportlern! Glück den Fans!"

Hier nicht an Maxim Gorki und den Weißmeerkanal zu denken, ist unmöglich. Gorki reiste 1933 zusammen mit Alexej Tolstoj, Boris Pilnjak, Ilf und Petrow, Soschtschenko und anderen sowjetischen Schriftstellern an den von Gulaghäftlingen oft buchstäblich mit ihren Händen gegrabenen Wasserweg von Leningrad ans Weiße Meer. Unter seiner, des unangefochtenen Doyens der sowjetischen Literatur jener Zeit Herausgeberschaft verfassten sie eine verlogene Eloge auf den Bau des Kanals.

Was treibt nun den »eigentlich" dem liberalen, putinkritischen, »europäischen« Lager des russischen Politik- kosmos zugerechneten Jerofejew dazu, Putin unverhohlen mit dem "guten Stalin« zu vergleichen (im deutschen Kontext: dem, der die Autobahnen gebaut hat)? Möchte er sich eventuell mit dem großen Gorki gleichsetzen? Spürt er vielleicht mit feiner Nase, dass ein wenig vorauseilende Unterordnung dieser Tage angebracht ist? Oder wird er dereinst allen Kritikern spöttisch entgegen halten, das sei doch alles hochironisch gemeint, und wie hätte auch nur irgendjemand mit Verstand das ernst nehmen können?

Natürlich ist Putin kein Stalin und Russland nicht die Sowjetunion. Allein der Hauch eines Vergleichs führt analytisch in die Irre. Die heutigen Herrscher Russlands sind geldgeile Kapitalisten und keine Revolutionäre. Aber das (jeweils eigene) Bild Stalins in allen russischen Köpfen ist so groß und wirkmächtig, dass nur wenige der Versuchung wiederstehen können, mit ihm zu spielen, es (aus)zu nutzen. Was auch immer sich Jerofejew mit diesem Sowjetstyle-Text gedacht hat: Es lässt nichts Gutes ahnen.

Diesen und andere Texte finden Sie aufJens Siegerts Russlandblog <http://russland.boellblog.org/>.

Grafik 13: Würden Sie die Olympischen Winterspiele in Sotschi gerne besuchen? Wenn ja, glauben Sie, dass Ihnen das gelingt?

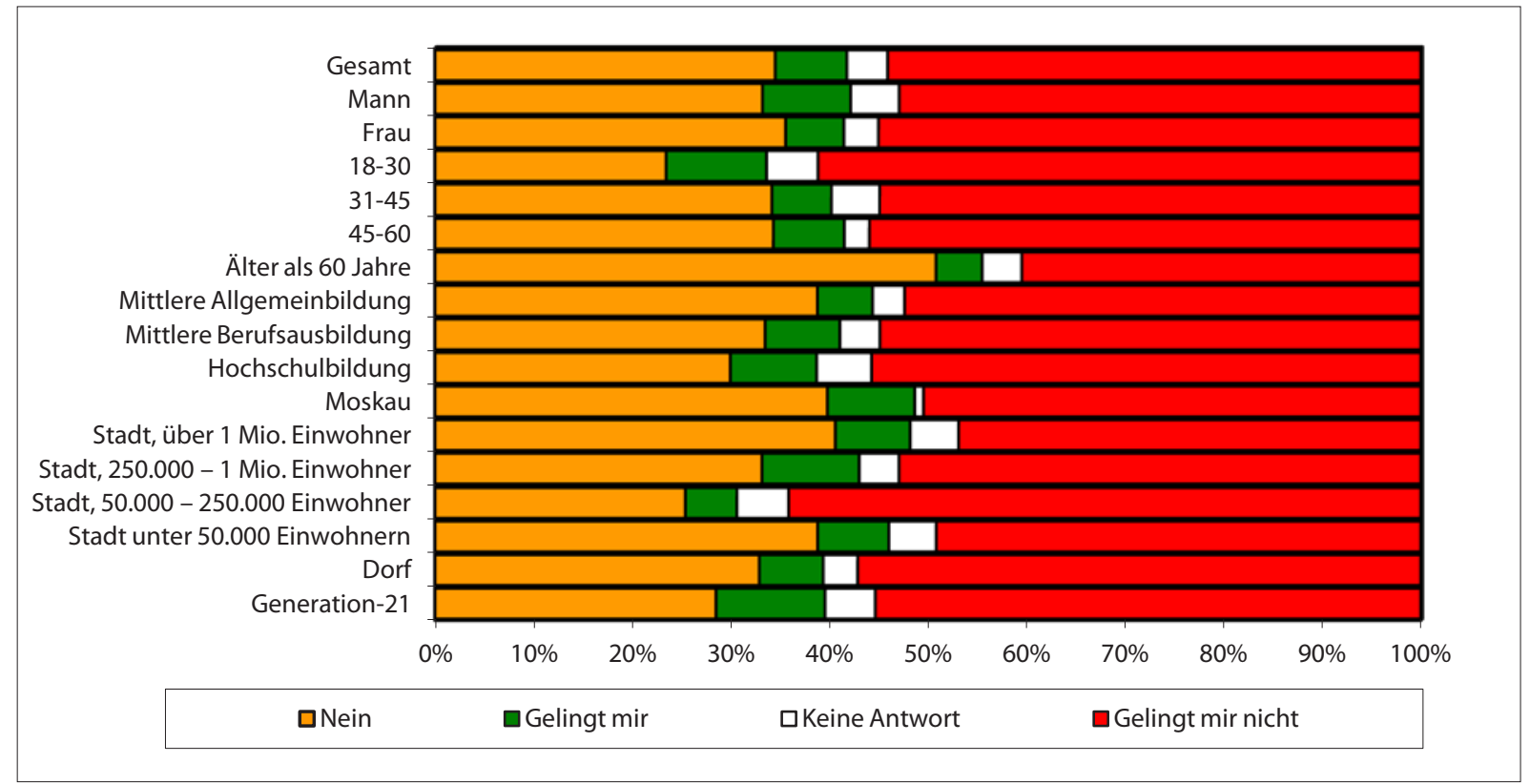

Quelle: Umfragen der Stiftung Öffentliche Meinung vom 12.-13. Oktober 2013, N=1500. Veröffentlicht am 28. Oktober 2013 unter: <http://fom.ru/obshchestvo/11159>. 


\section{Vom 22. November bis zum 5. Dezember 2013}

\begin{tabular}{|c|c|}
\hline 22.11.2013 & $\begin{array}{l}\text { Wladislaw Baumgertner, Generaldirektor des Unternehmens »Uralkali«, wird von Belarus nach Moskau ausge- } \\
\text { liefert und dort in Untersuchungshaft überführt. Baumgertner war Ende August in Minsk festgenommen wor- } \\
\text { den. Die belarussischen Behörden warfen ihm vor, als Aufsichtsratsvorsitzender der Belarusian Potash Company } \\
\text { (BPC) sein Amt missbraucht und Belarus Schaden zugefügt zu haben. }\end{array}$ \\
\hline 22.11 .2013 & $\begin{array}{l}29 \text { der } 30 \text { Greenpeace-Aktivisten werden gegen Zahlung einer Kaution von jeweils } 2 \text { Million Rubel (ca. } 45.000 € \text { ) } \\
\text { aus der Untersuchungshaft in St. Petersburg entlassen. In Hamburg entscheidet der Internationale Seegerichts- } \\
\text { hof, dass Russland das Schiff sowie die Besatzung der "Arctic Sunrise« unverzüglich freizugeben habe. Russland } \\
\text { erkennt das Urteil nicht an. }\end{array}$ \\
\hline 22.11.2013 & $\begin{array}{l}\text { Die russische Staatsduma verabschiedet in dritter Lesung eine Gesetzesnovelle, mit der die Zusammenlegung des } \\
\text { Obersten Gerichtshofes und des Obersten Arbitragegerichts verfügt wird. }\end{array}$ \\
\hline 22.11.2013 & $\begin{array}{l}\text { Sergej Kriwow, Angeklagter im »Bolotnaja-Verfahren«, beendet seinen zweimonatigen Hungerstreik und wird in } \\
\text { die Krankenstation eines Moskauer Untersuchungsgefängnisses verlegt. Zuvor hatte der Europäische Gerichts- } \\
\text { hof für Menschenrechte die Regierung Russlands aufgefordert, ihn über Zustand des Untersuchungsgefangenen } \\
\text { und seine medizinische Betreuung zu informieren. }\end{array}$ \\
\hline 23.11.2013 & $\begin{array}{l}\text { Ministerpräsident Dmitrij Medwedew unterzeichnet eine Anweisung, wonach russische Goldmedaillengewinner } \\
\text { bei den Olympischen Winterspielen in Sotschi } 4 \text { Mio. Rubel (ca. 89.000 €) Preisgeld erhalten. Für eine Silberme- } \\
\text { daille werden 2,5 Mio. Rubel (ca. 56.000 €), für eine Bronzemedaille 1,7 Mio. Rubel (ca. } 38.000 € \text { ) Preisgelder } \\
\text { an russische Sportler vergeben. Derweil geht die Olympische Fackel auf Tauchgang zum Grund des Baikalsees. }\end{array}$ \\
\hline 25.11.2013 & $\begin{array}{l}\text { Präsident Wladimir Putin erhält eine Audienz bei Papst Franziskus in Rom. Im Anschluss trifft er mit dem ita- } \\
\text { lienischen Staatspräsidenten Giorgio Napolitano zusammen. Im Zentrum stehen die wirtschaftlichen Beziehun- } \\
\text { gen sowie die Situation in Nahost. }\end{array}$ \\
\hline 25.11.2013 & $\begin{array}{l}\text { Bei einer Polizeirazzia nach illegalen »Gastarbeitern« werden im Einkaufszentrum »Moskau« im Moskauer Stadt- } \\
\text { teil Ljublino } 700 \text { Personen festgenommen. }\end{array}$ \\
\hline 26.11.2013 & $\begin{array}{l}\text { Präsident Wladimir Putin trifft in Triest mit dem italienischen Ministerpräsidenten Enrico Letta zusammen. Bei } \\
\text { Gesprächen werden mehrere Abkommen unterzeichnet, u. a. eine Vereinbarung über ein gemeinsames Jahr des } \\
\text { Tourismus zwischen Russland und Italien 2013-2014. Vor dem Treffen war Putin informell mit dem ehemali- } \\
\text { gen Ministerpräsidenten Silvio Berlusconi zusammengetroffen. }\end{array}$ \\
\hline 26.11.2013 & $\begin{array}{l}\text { Die Schokoladenprodukte des ukrainischen Unternehmens »Roshen« dürfen wieder nach Russland importiert } \\
\text { werden. Die russische Lebensmittelkontrollbehörde hatte Ende Juli die Qualität der Waren in Frage gestellt und } \\
\text { einen Einfuhrstopp verhängt. }\end{array}$ \\
\hline $\begin{array}{l}\text { 26.- } \\
27.11 .2013\end{array}$ & $\begin{array}{l}\text { In einem Vorort von Machatschkala (Dagestan) werden drei Untergrundkämpfer bei einem Sondereinsatz der } \\
\text { Sicherheitskräfte getötet, u. a. der Anführer der Kämpfer im Rayon Kaspijsk. }\end{array}$ \\
\hline 27.11 .2013 & $\begin{array}{l}\text { Nach Protesten wird ein Ausstellungspavillon in Form eines Louis-Vuitton-Koffers entfernt, der aus Werbezwecken } \\
\text { auf dem Roten Platz aufgebaut wurde. Die Präsidialadministration erklärt, sie habe keine Genehmigung erteilt. }\end{array}$ \\
\hline 27.11.2013 & $\begin{array}{l}\text { Das russische Innenministerium teilt mit, dass in Moskau } 15 \text { Anhänger der extremistischen Organisation »Tak- } \\
\text { fir wa'l-Higra" festgenommen wurden. Dabei habe man auch Sprengsätze und Waffen konfisziert. }\end{array}$ \\
\hline 27.11.2013 & Bei einem Sondereinsatz der Sicherheitskräfte in Nasran (Inguschetien) werden zwei Untergrundkämpfer getötet. \\
\hline 28.11.2013 & $\begin{array}{l}\text { Das Strafverfolgungskomitee eröffnet ein weiteres Strafverfahren gegen den ehemaligen Verteidigungsminister } \\
\text { Anatolij Serdjukow. Man wirft ihm Vernachlässigung der Dienstpflichten vor, da in seinem Verantwortungsbe- } \\
\text { reich durch Veruntreuung von Haushaltsmitteln ein Schaden von } 56 \text { Mio. Rubel (ca. 1,2 Mio. €) entstanden sei. }\end{array}$ \\
\hline 28.11.2013 & $\begin{array}{l}\text { Der letzte der Greenpeace-Aktivisten der "Arctic Sunrise» wird gegen eine Kaution von } 2 \text { Million Rubel (ca. } \\
44.400 € \text { ) aus der Untersuchungshaft entlassen. }\end{array}$ \\
\hline 28.11.2013 & $\begin{array}{l}\text { Präsident Wladimir Putin wird in Sotschi über den Vorbereitungsstand der Olympiade unterrichtet. Er erklärt, } \\
\text { dass die Neujahrsfeiertage für alle Verantwortlichen der Winterspiele erst zum letzten Tag der Paralympics am } \\
\text { 18. März } 2014 \text { beginnen. }\end{array}$ \\
\hline 29.11.2013 & $\begin{array}{l}\text { Ein Moskauer Bezirksgericht verlängert die Untersuchungshaft des ehemaligen Bürgermeisters von Jaroslawl } \\
\text { Jewgenij Urlaschow bis zum 3. März 2014. Urlaschow war Anfang Juli unter dem Vorwurf der Erpressung und } \\
\text { Bestechlichkeit festgenommen worden. }\end{array}$ \\
\hline 30.11 .2013 & $\begin{array}{l}\text { Natalja Gorbanewskaja, Dichterin, Übersetzerin, Menschenrechtlerin und Mitglied der sowjetischen Dissiden- } \\
\text { tenbewegung stirbt im Alter von } 77 \text { Jahren in Paris. Gorbanewskaja wurde nach der Demonstration vom } 25 . \\
\text { August } 1968 \text { gegen den Einmarsch von Truppen des Warschauer Pakts in die Tschechoslowakei zwangsweise in } \\
\text { die Psychiatrie eingeliefert, durfte aber } 1975 \text { nach Paris emigrieren. }\end{array}$ \\
\hline
\end{tabular}




\begin{tabular}{|c|c|}
\hline 02.12 .2013 & $\begin{array}{l}\text { Präsident Wladimir Putin trifft zu einem Staatsbesuch in Armenien ein. Nach einem Besuch der russischen Mili- } \\
\text { tärbasis bespricht er mit seinem Amtskollegen Sersch Sargsjan die bilaterale Zusammenarbeit und den Beitritt } \\
\text { Armeniens zur Zollunion und dem Einheitlichen Wirtschaftsraum. Als Anreiz wird Armenien der Exportzoll } \\
\text { auf russische Energieträger erlassen und der Gaspreis auf } 189 \text { US-Dollar pro } 1.000 \mathrm{~m}^{3} \text { reduziert. Zudem über- } \\
\text { nimmt Gazprom die letzten } 20 \% \text { der Anteile von "Armrosgazprom«, dem armenischen Gasnetzbetreiber, und } \\
\text { erlässt im Gegenzug } 155 \text { Mio. US-Dollar Gasschulden. }\end{array}$ \\
\hline 02.12 .2013 & $\begin{array}{l}\text { Präsident Putin unterzeichnet einen Erlass zur Gründung des »Vereinigten Raketen- und Weltraumkorpora- } \\
\text { tion« (ORKK), das alle Staatsunternehmen der Raketen- und Raumfahrttechnik vereinen soll. Bei der födera- } \\
\text { len Agentur »Roskosmos« verbleiben jedoch die wissenschaftlichen Einrichtungen und die Bodeninfrastruktur. }\end{array}$ \\
\hline 02.12 .2013 & $\begin{array}{l}\text { äsident Putin unterzeichnet den Föderalen Haushalt für } 2014 \text { und den Haushaltsplan für 2015-2016. Dieser } \\
\text { ht im Jahr } 2014 \text { Einnahmen von 13,57 Billionen Rubel (ca. 300,4 Mrd. €) bei Ausgaben um die 13,96 Billio- } \\
\text { n Rubel (ca. } 309 \text { Mrd. €) vor. Das Defizit soll 389,6 Mrd. Rubel (ca. 8,6 Mrd. €) oder 0,5\% des BIP betra- } \\
\text { n, das sich } 2014 \text { auf 73,315 Billionen Rubel (ca. 1,6 Billionen €) bei einer Inflationsrate von } 5 \% \text { belaufen soll. }\end{array}$ \\
\hline 03.12 .2013 & $\begin{array}{l}\text { Transparency International veröffentlicht den »Korruptionswahrnehmungsindex« für 2013. Russland verbessert } \\
\text { ich bei gleicher Vorjahreswertung um sechs Plätze auf den 127. Platz, gleichauf mit Pakistan, Mali, Madagas- } \\
\text { xar und Aserbaidschan. }\end{array}$ \\
\hline 03.12 .2013 & $\begin{array}{l}\text { Moskauer Bezirksgericht verurteilt drei Personen wegen des Säureanschlags auf den Ballettmeister des Bol- } \\
\text { noj Theaters Sergej Filin. Pawel Dmitritschenko, Tänzer am Theater, erhält als Organisator sechs Jahre, der } \\
\text { entliche Täter zehn und der Fahrer vier Jahre Haft. }\end{array}$ \\
\hline 03.12 .2013 & $\begin{array}{l}\text { Präsident Wladimir Putin stellt sich in der Moskauer Staatlichen Universität (MGU) zum »Tag der Juristen« } \\
\text { den patriotischen Fragen von Jurastudenten aller Moskauer Universitäten. Im Anschluss nimmt er an der ersten } \\
\text { Kuratoriumssitzung der MGU teil, deren Vorsitz er übertragen bekommt. Im Kuratorium sitzen mehrere Vor- } \\
\text { sitzende von Staatsunternehmen. }\end{array}$ \\
\hline 04.12 .2013 & $\begin{array}{l}\text { Genri Resnik, Präsident der Moskauer Anwaltskammer, bestätigt den Entzug des Anwaltsmandates des Bloggers } \\
\text { und Oppositionsaktivisten Alexej Nawalnyj wegen der Bewährungsstrafe im »Kirowles«-Verfahren. Das Oberste } \\
\text { Gericht lehnt zudem eine Klage Nawalnyjs gegen das Wahlergebnis bei den Moskauer Bürgermeisterwahlen ab. }\end{array}$ \\
\hline 04.12 .2013 & $\begin{array}{l}\text { Ministerpräsident Dmitrij Medwedew empfängt den Stellvertretenden ukrainischen Ministerpräsidenten Jurij Bojko. } \\
\text { Im Zentrum des Gesprächs steht die Entwicklung der bilateralen Beziehungen unter anderem im Erdgassektor. }\end{array}$ \\
\hline 05.12 .2013 & $\begin{array}{l}\text { Das Innenministerium teilt mit, im Moskauer Gebiet rund 2,500 illegale Gastarbeiter in einer Textilfabrik fest- } \\
\text { genommen zu haben. Allein in Moskau hat sich } 2013 \text { die Zahl der Strafverfahren wegen illegaler Migration um } \\
\text { das Sechzigfache erhöht. }\end{array}$ \\
\hline 05.12 .2013 & $\begin{array}{l}\text { Präsident Wladimir Putin nimmt in Moskau an einer Konferenz der "Allrussischen Volksfront« zu den Themen } \\
\text { Wirtschaft, Gesundheitsfürsorge, Wohn- und Kommunalwirtschaft, Bildung und Kultur teil. }\end{array}$ \\
\hline
\end{tabular}

Sie können die gesamte Chronik seit 1964 auch auf<http://www.laender-analysen.de/russland/> unter dem Link »Chronik«lesen.

Die Russland-Analysen werden von der Alfried Krupp von Bohlen und Halbach-Stiftung und von Mangold Consulting GmbH unterstützt.

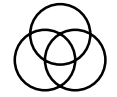

\section{Alfried Krupp von Bohlen und Halbach Stiftung}

\section{MANGOLD

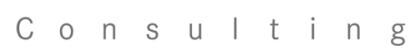

Herausgeber: Forschungsstelle Osteuropa an der Universität Bremen und Deutsche Gesellschaft für Osteuropakunde

Die Meinungen, die in den Russland-Analysen geäußert werden, geben ausschließlich die Auffassung der Autoren wieder. Abdruck und sonstige publizistische Nutzung sind nach Rücksprache mit der Redaktion gestattet. Verantwortlicher Redakteur: Hans-Henning Schröder

Recherche, Übersetzungen und Sprachredaktion: Christoph Laug, Hartmut Schröder Satz: Matthias Neumann

Russland-Analysen-Layout: Cengiz Kibaroglu, Matthias Neumann und Michael Clemens

Alle Ausgaben der Russland-Analysen sind mit Themen- und Autorenindex archiviert unter www.laender-analysen de

Die Russland-Analysen werden im Rahmen eines Lizenzvertrages in das Internetangebot der Bundeszentrale für politische Bildung (www.bpb.de) aufgenommen.

Die Russland-Analysen werden im Rahmen der Datenbank World Affairs Online (WAO) ausgewertet und sind im Portal IREON www.ireon-portal.de recherchierbar. ISSN 1613-3390 (c) 2013 by Forschungsstelle Osteuropa, Bremen

Forschungsstelle Osteuropa • Publikationsreferat • Klagenfurter Str. 3 • 28359 Bremen • Telefon: +49 421-218-69600 • Telefax: + 49 421-218-69607 e-mail: publikationsreferat@osteuropa.uni-bremen.de•Internet-Adresse: http://www.laender-analysen.de/russland/ 


\section{Kostenlose E-Mail-Dienste der Forschungsstelle Osteuropa und ihrer Partner auf www.laender-analysen.de}

Die Länder-Analysen bieten regelmäßig kompetente Einschätzungen aktueller politischer, wirtschaftlicher, sozialer und kultureller Entwicklungen in Ostmitteleuropa und der GUS. Sie machen das Wissen, über das die wissenschaftliche Forschung in reichem Maße verfügt, für Politik, Wirtschaft, Medien und die interessierte Öffentlichkeit verfügbar. Autoren sind internationale Fachwissenschaftler und Experten.

Die einzelnen Länder-Analysen werden von der Forschungsstelle Osteuropa an der Universität Bremen und der Deutschen Gesellschaft für Osteuropakunde jeweils mit unterschiedlichen Partnern und Sponsoren herausgegeben.

Die Länder-Analysen bieten regelmäßig Kurzanalysen zu aktuellen Themen, ergänzt um Grafiken und Tabellen sowie Dokumentationen. Zusätzlich gibt es eine Chronik aktueller Ereignisse.

\section{Belarus-Analysen}

Erscheinungsweise: zweimonatlich

Abonnement unter: fsopr@uni-bremen.de

\section{Caucasus Analytical Digest}

In englischer Sprache. Erscheinungsweise: monatlich

Abonnement unter: http://www.res.ethz.ch/analysis/cad/

\section{Polen-Analysen}

Erscheinungsweise: zweimal monatlich

Abonnement unter: http://www.deutsches-polen-institut.de/Newsletter/subscribe.php

\section{Russland-Analysen}

Erscheinungsweise: zweiwöchentlich

Abonnement unter: fsopr@uni-bremen.de

\section{Russian Analytical Digest}

In englischer Sprache. Erscheinungsweise: zweimal monatlich

Abonnement unter: http://www.res.ethz.ch/analysis/rad/

Ukraine-Analysen

Erscheinungsweise: zweimal monatlich

Abonnement unter: fsopr@uni-bremen.de

\section{Zentralasien-Analysen}

Erscheinungsweise: monatlich

Abonnement unter: zentralasien-analysen@dgo-online.org

\section{Bibliographische Dienste}

Die Bibliographien informieren über englisch- und deutschsprachige Neuerscheinungen zu Belarus, Polen, Russland, Tschechischer und Slowakischer Republik, Ukraine sowie zu den zentralasiatischen und kaukasischen Staaten. Erfasst werden jeweils die Themenbereiche Politik, Außenpolitik, Wirtschaft und Soziales.

Erscheinungsweise: viermal jährlich

Abonnement unter: fsopr@uni-bremen.de 